\title{
Review Article \\ Progress in Research on Carbon Nanotubes Reinforced Cementitious Composites
}

\author{
Qinghua Li, Jintao Liu, and Shilang Xu \\ Institute of Advanced Engineering Structures and Materials, Zhejiang University, Hangzhou 310058, China \\ Correspondence should be addressed to Qinghua Li; liqinghua@zju.edu.cn
}

Received 27 April 2015; Revised 12 July 2015; Accepted 13 July 2015

Academic Editor: Robert Cerný

Copyright (C) 2015 Qinghua Li et al. This is an open access article distributed under the Creative Commons Attribution License, which permits unrestricted use, distribution, and reproduction in any medium, provided the original work is properly cited.

\begin{abstract}
As one-dimensional (1D) nanofiber, carbon nanotubes (CNTs) have been widely used to improve the performance of nanocomposites due to their high strength, small dimensions, and remarkable physical properties. Progress in the field of CNTs presents a potential opportunity to enhance cementitious composites at the nanoscale. In this review, current research activities and key advances on multiwalled carbon nanotubes (MWCNTs) reinforced cementitious composites are summarized, including the effect of MWCNTs on modulus of elasticity, porosity, fracture, and mechanical and microstructure properties of cement-based composites. The issues about the improvement mechanisms, MWCNTs dispersion methods, and the major factors affecting the mechanical properties of composites are discussed. In addition, large-scale production methods of MWCNTs and the effects of CNTs on environment and health are also summarized.
\end{abstract}

\section{Introduction}

Concrete has been widely used in the field of civil engineering, and it has been reported that 3.3 billion tonnes of cement was produced worldwide in 2010 [1]. Generally, the main disadvantage of traditional cement-based materials is low tensile strength and being easy to crack, which seriously affects the strength, durability, and safety of concrete structures $[2,3]$. According to previous studies, the tensile strength of plain concrete lies in the range of 2-8 MPa [4]. Therefore, many kinds of fibers were used to improve the toughness of cement-based materials by delaying the transformation of cracks. These fibers increased tensile strength and diffused large cracks into a dense of macrocracks, but there was little effect in delaying microcrack initiation [5-9].

With the development of nanotechnology, concrete can be modified by the incorporation of nanosized additives to improve material behavior and add some special properties [10]. For example, as zero-dimensional (0D) nanomaterials, nanoparticles can act as nuclei for cement hydration and densify the microstructure of hydration products due to their high reactivity. Although the ultimate strength of nanocomposite is improved by these nanoparticles, they offer little resistance to microcrack propagation [11-13]. As one-dimensional (1D) fiber [14], the research on mechanical, chemical, electrical, and other properties of CNTs has acquired remarkable advances. The CNTs consist of one or up to dozens of graphitic shells seamlessly wrapped into a cylindrical tube; thus, it can be divided into two groups: multiwalled carbon nanotubes (MWCNTs) and single-walled carbon nanotubes (SWCNTs) $[15,16]$. Van der Waals force holds sheets of hexagonal networks parallel with each other with a spacing of $0.34 \mathrm{~nm}$, and the diameters of CNTs are between 2 and 100 nanometers [17]. Figure 1 shows TEM images of homogeneous nanotubes of hexagonal network.

The strength, toughness, and specific surface area of CNTs are far superior to those of traditional fibers that may improve the toughness of cementitious materials at nanoscale [1720]. Research achievements indicate that CNTs have provided exciting opportunity to improve the performance of cementbased materials [1, 10, 21-25]. However, SWCNTs are rarely used to reinforce cement-based materials due to their high price. So this paper mainly reviews the developments in the field of MWCNTs research in cement-based materials, along with their key findings and applications. Meanwhile, the properties of the fresh and hardened nanocomposites including microstructure, dispersion, workability, and mechanical properties are also discussed. 
TABLE 1: Material properties of typical fibers.

\begin{tabular}{|c|c|c|c|c|c|c|c|c|}
\hline Material & $\begin{array}{l}\text { Diameter/thickness } \\
(\mathrm{nm})\end{array}$ & $\begin{array}{c}\text { Elastic } \\
\text { modulus } \\
(\mathrm{GPa})\end{array}$ & $\begin{array}{c}\text { Tensile } \\
\text { strength } \\
(\mathrm{GPa})\end{array}$ & $\begin{array}{c}\text { Rupture } \\
\text { Elongation } \\
(\%)\end{array}$ & $\begin{array}{l}\text { Density } \\
\left(\mathrm{kg} / \mathrm{m}^{3}\right)\end{array}$ & $\begin{array}{l}\text { Surface area } \\
\left(\mathrm{m}^{2} / \mathrm{g}\right)\end{array}$ & Aspect ratio & Reference \\
\hline Carbon fiber & $6000-20,000$ & $7-400$ & $0.4-5$ & 1.7 & 1770 & 0.134 & $100-1000$ & {$[145,146]$} \\
\hline Polymeric fiber & $18,000-30,000$ & $3-5$ & $0.3-0.9$ & 18 & 900 & 0.225 & $160-1000$ & {$[147,148]$} \\
\hline Glass fiber & $5000-10,000$ & 72 & 3.45 & 4.8 & 2540 & 0.3 & $600-1500$ & {$[149,150]$} \\
\hline Steel fiber & $50,000-900,000$ & 200 & 1.5 & 3.2 & 7800 & 0.02 & $45-80$ & {$[151,152]$} \\
\hline $\mathrm{CNTs}$ & $10-60$ & 1000 & $11-63$ & 12 & 1330 & $70-400$ & $1000-10000$ & {$[26,38]$} \\
\hline
\end{tabular}

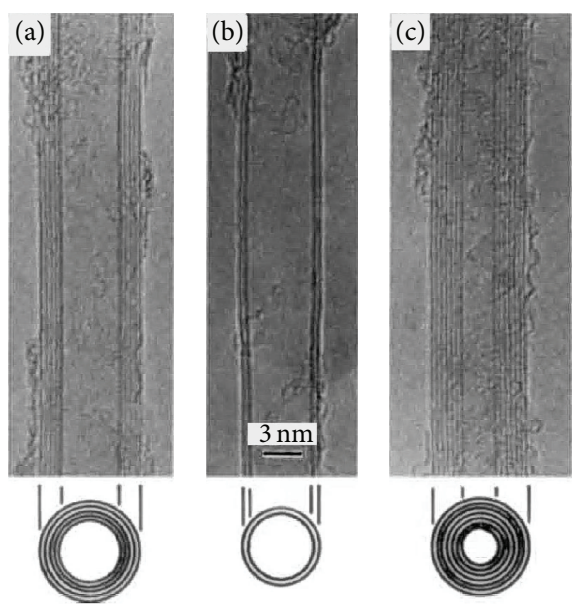

FIGURE 1: Homogeneous nanotubes of hexagonal network: TEM images (a), (b), and (c) for three multiwalled nanotubes (MWNTs) [17].

\section{Properties of CNTs}

2.1. Mechanical Properties. Microfibers, such as carbon and steel fibers, are widely used in the construction industry owing to their high elastic modulus and tensile strength, and the material properties of typical fibers are summarized in Table 1. It can be concluded that CNTs possess superior tensile strength and elastic modulus when compared to traditional fibers. The strength of fiber-reinforced composites is greatly affected by fiber aspect ratio, which is expected to be more than 20. The aspect ratio of CNTs ranges from 1000 to 10000 , which make it an ideal choice as a fiber-reinforced material. CNTs also have very high strength, toughness, and Young's modulus because of the carbon-carbon $\mathrm{sp}^{2}$ bonding. The density of CNTs is only one-sixth of steel, but the tensile strength is estimated at tens of GPa, which is 100 times higher than that of steel [26]. Young's modulus of CNTs is around $1 \mathrm{TPa}$ and the fracture strain is as high as $280 \%$; for comparison, Young's modulus of high strength steel is around $200 \mathrm{GPa}$ and the fracture strain is less than $30 \%$. Although the tensile strength of CNTs with the ideal structure can reach $800 \mathrm{GPa}$, weak shear interactions between adjacent tubes lead to significant reductions in the effective tensile strength of MWCNTs [27, 28].
2.2. Number of Walls, Diameter, and Length. MWCNTs consist of up to several tens of graphitic shells, and they have diameters of 2-100 $\mathrm{nm}$ and lengths ranging from tens of nanometers to several microns. The length of MWCNTs is particularly important for multiscale hybrid composites, since they are expected to improve mechanical properties. Delmas et al. [29] reported the growth of well-aligned and long MWCNTs, and tube length could easily be tuned between 100 and $350 \mu \mathrm{m}$. Recently, the final growth length of MWCNTs was found to be about $10 \mathrm{~mm}$, and the growth length of the arrays increased linearly with the increase of growth time followed by an abrupt termination [30]. However, the millimeter long MWCNTs arrays represented a significant advance in the development of multiscale composite properties [31, 32].

The density of MWCNTs changes along with the diameter, number of walls, and the length. Therefore, both the weight and density of MWCNTs vary over a very wide range depending on the number of walls, inner diameter, or outer diameter. Kim et al. [33] have reported that the measured density of MWCNTs is equal to $1.74 \pm 0.16$ (outer diameter about $22 \mathrm{~nm}$ ). Laurent et al. [34] established the relations between the weight and the density of CNTs and their geometrical characteristics (inner diameter, outer diameter, and number of walls), which were useful to other researchers. A MWCNT consists of concentrically nested cylinders with an interlayer spacing of $3.4 \AA$ and a diameter typically on the order of 10-20 nm [35]. The wall count in MWCNT basically depends on their size. Chiodarelli et al. [36] proposed an empirical law correlating the average number of walls and the average diameter in a population of MWCNTs grown by catalytic chemical vapor deposition. Based on this approach, it is easy to estimate the number of walls most likely present in a population of nanotubes only from the measurement of their average diameter.

2.3. Specific Surface Area. Owing to its particular structure, a CNT has a very large SSA (specific surface area) as high as $790 \mathrm{~m}^{2} / \mathrm{g}$, and high SSA can remarkably enhance the activity of CNTs [37]. The theoretical SSA of MWCNTs mainly depended on the diameter and number of walls; moreover, the SSA of CNTs bundle decreases when the number of CNTs is increasing. However, most of MWCNTs have much lower surface area than the theoretical value. Peigney et al. calculated the theoretical external SSA of 
MWCNTs as a function of their characteristics (e.g., diameter, number of walls, and number of nanotubes in a bundle), and SAA measurements can be efficiently used to optimize the synthesis of CNTs [38].

2.4. Defects and Cutting. Although a lot of methods have been used for preparation of CNTs, defects inevitably exist on the surface of CNTs. The appearance of these defects leads to the decrease in mechanical properties of CNTs and thus affects the performance of the nanocomposite. Most attempts have concentrated on the role of defects in limiting peak strengths and the Stone-Wales (SW) defect [39]. The aggregations of SW defects could be followed by a ringopening mechanism that would permit the nucleation of a crack [40]. It was observed that the defect produced stress and strain concentration effects in the vicinity of the defect due to changes in the geometric configuration and concomitant force fields. The local stiffness dropped by around 40 percent in the defected region, and this decrease could be attributed to the changes in the kinetics and kinematics in the vicinity of the defects [41]. This explains why the fracture strain of CNTs obtained by molecular dynamics $(10 \%-13 \%)$ is much higher than the experimental results (13\%) [42]. Moreover, vacancy fraction, eccentricity, orientation, and interaction of defects are also found to be the key parameters influencing the stiffness degradation [43, 44]. Mielke et al. [45] explored the role that vacancy defects in the fracture of CNTs and one- and two-atom vacancy defects were observed to reduce failure stresses by as much as $26 \%$ and markedly reduce failure strains; moreover, large holes greatly reduced strength.

The aggregation of long MWCNTs in the matrix is a critical behavior affecting the mechanical performance of composites. Generally, better dispersion of MWCNTs in matrix can be achieved by cutting of long MWCNTs [46]. Adopting this method, MWCNTs can be greatly reduced in length and disentangled, being straighter with open ends [47]. There have been three methods of cutting MWCNTs, including physical methods (ball grinding and ultrasonic degradation), chemical methods (liquid-phase oxidation and solid-phase oxidation), and combined methods (electronic induction cutting, ball grinding, and liquid-phase oxidation of cutting method and multistep control method) [48-52].

2.5. Electrical Properties. CNTs can be classified into metallic and semiconducting types based on different electronic properties. Because CNTs are rolled-up sheets of graphite, electricity experiment shows that they have very little resistance. Therefore, it is an ideal material for the electrodes of double electric layer capacitors due to its lightweight, large effective specific surface area, and high conductivity. For example, researchers have applied the feature of CNTs such as large specific surface area and excellent conductivity into the field of electrochemistry and produced a lot of electrochemical sensors, super capacitors, and so on [53]. MWCNTs composed of carbon atoms can be considered approximately as one-dimensional systems with nanostructures; moreover, MWCNTs can pass a very high current density from $10^{6}$ to $2.4 \times 10^{8} \mathrm{~A} / \mathrm{cm}^{2}$ without adverse effects $[54,55]$. The intrinsic mobility can exceed $10^{5} \mathrm{~cm}^{2} \mathrm{~V}^{-1} \mathrm{~s}^{-1}$ at room temperature, which is greater than any other known semiconductors [56].

\section{Dispersion of MWCNTs}

MWCNTs have an extremely high specific surface area up to $200 \mathrm{~m}^{2} / \mathrm{g}$, and they are prone to reunite and form MWCNT bundle structures because of their high surface energy. Dispersion of MWCNTs in cementitious materials is a critical issue, which strongly influences the performance of cement-based nanocomposites $[57,58]$. If the initial bundles are not separated into single roots, then these MWCNTs aggregations may emerge later as matrix defects in the composites. In addition, it has been proved that the conventional concrete mixers cannot be used to disperse MWCNTs into cement paste directly [59]. To improve the dispersivity, MWCNTs are usually dispersed into water firstly, and then MWCNTs/water solution and cement particles are mixed using a conventional mixer. Currently, physical modification and chemical modification are two main methods commonly used for the dispersion of MWCNTs in water.

3.1. Physical Methods. Uniform dispersion is attainable using various types of mechanical methods, including ultrasonication, ball milling, and rubbing [60]. A 120-litre-capacity basket mill filled with $0.8 \mathrm{~mm}$ zirconium oxide beads was operated at $900 \mathrm{rpm}$ to disperse $3.0 \mathrm{wt} \%$ MWNT for $7 \mathrm{~h}$, and the dispersion of MWNTs was achieved in the form of condensed solution [61]. It was also observed that MWCNTs were damaged in different ways during ball milling, and a large amount of amorphous carbon was created [62]. Compared with the ball milling method, the rubbing process that introduces cuts and bends in MWCNTs is more destructive.

Ultrasonication is another classic physical debundling method for MWCNTs dispersion [63, 64]. Liquid particles vibrate and produce small cavities when the ultrasonic wave transmits through liquid. Rapid swelling and closing of these small cavities result in liquid particles dashing against each other violently with pressures of tens of thousands of atmospheres produced at microscopic scales. Carbon nanotube bundles are gradually dispersed with such cavitation. In order to make MWCNTs disperse better in the water, ultrasonication process may take a few minutes or even hours $[65,66]$. Bryan et al. used a liquid processor ultrasonic mixer (Vibra-Cell, model VC-505) to disperse the MWCNTs which were sonicated for $30 \mathrm{~min}$. Figure 2 shows the TEM image of CNTs after dispersion which indicate that ultrasonic can debond MWCNTs $[67,68]$. Constant ultrasonication energy is usually applied to disperse MWCNTs by using high intensity ultrasonic processor [69]. Metaxa et al. studied the effect of different ultrasonication energies (2100, 2800, and $3500 \mathrm{~kJ} / \mathrm{L}$ ) on the strength of the nanocomposite and found that $2800 \mathrm{~kJ} / \mathrm{L}$ was the best choice [70]. In another study, the sonicator was operated at amplitude of $50 \%$ so as to deliver energy of 1900-2100 J/min at cycles of $20 \mathrm{~s}$ in order to prevent overheating of the suspensions $[71,72]$. However, low ultrasonic energies cannot ensure homogeneous distribution of MWCNTs whereas high-energy input shortens the length 


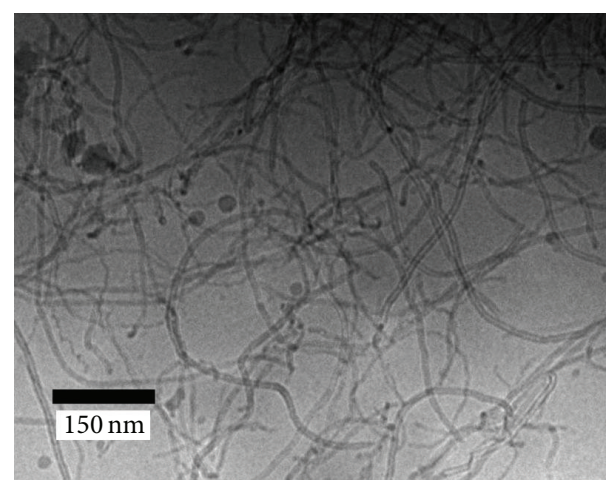

FIgURE 2: TEM image of CNTs dispersed in an aqueous solution [67].

of MWCNTs, as shown in Figure 3. Therefore, the duration and power of sonication must be strictly controlled, in order to avoid physical damage and fracture of the MWCNTs. In addition, since MWCNTs will reagglomerate due to the van der Waals forces over time, centrifuge is employed to solve this problem. The high-speed rotation yields strong forces which accelerate the settling of MWCNTs at the bottom of the container, and the upper fraction of the fluid contains welldispersed MWCNTs [73, 74].

3.2. Chemical Methods. Surface chemical modification technology of MWCNTs is an important way to influence the interaction between the tubes and the surroundings, and these methods improve the hydrophilic behavior of MWCNTs while reducing their tendency to form agglomerates [24]. One of the common methods is acid treatment that is used to oxidize MWCNTs and produce carboxylic acid and hydroxyl groups. In a study by Li et al., MWCNTs were added into the mixed solution of sulfuric acid and nitric acid ( $3: 1$ by volume, resp.), and the FT-IR spectrum result indicated the treatment by strong oxidizing acid which caused the attachment of oxygen-containing groups to the surfaces of MWCNTs [66]. Polycarboxylate, which is commonly used as water reducer within concrete, is also found to be an effective dispersant of MWCNTs $[75,76]$, and it can disperse the MWCNTs to a uniformly black opaque solution that remained unchanged when observed at 9 days [77]. Besides acid treatment, various surfactants are also employed to obtain a proper dispersion of MWCNTs in water and subsequently within cement, such as gum arabic (GA), sodium deoxycholate (NaDC), sodium dodecyl benzene sulfonate (SDBS), triton X-100 (TX10), and cetyl trimethyl ammonium bromide (CTAB) $[65,74,78-$ 80]. Luo et al. used five surfactants to enhance solubilization/dispersion of MWCNTs in aqueous solution and cement matrix, and the results showed that the capability of superficial active agents (SAAs) in dispersing MWCNTs roughly decreases in the order as SDBS\&TX10, SDBS, NaDC\&TX10, $\mathrm{NaDC}, \mathrm{AG}, \mathrm{TX10}$, and CTAB [78].

Researchers used chemical vapor deposition method and microwave irradiating conductive polymers method to make MWCNTs and cement admixture a whole by in situ growing MWCNTs on the cement admixture particles [8183]. Ludvig et al. employed CVD method to grow CNTs on the cement clicker, and the results showed that the clinkerCNTs composite contained high purity MWCNTs and a CNTs yield of $4.03 \%$ in mass of particles-CNTs composite was obtained [84]. However, further research is needed to understand the influences of CNTs-grown cement particles on the hydration, mechanical performance, and modification mechanism of composites [85]. Generally, the dispersion of MWCNTs in cement-based material is still a critical issue, and it is necessary to find an easy, large-scale, and low energy method to distribute MWCNTs in cement. Currently, the combination of ultrasonication and surface modification of MWCNTs appears as the most promising method.

\section{Effect of CNTs on Cement-Based Material}

The size of Portland cement particles is usually between 7 and 200 micrometers, and calcium silicate hydrate (C-S$\mathrm{H})$ is the main hydration product of Portland cement that is responsible for its mechanical properties [86]. Hydration products include amorphous crystals and crystal water from nanometer to micrometer scale, and $70 \%$ of the products from the hydration of $\mathrm{C}-\mathrm{S}-\mathrm{H}$ gel particles are nanomaterials [87]. C-S-H gels are a kind of colloidal material which are held together mainly by van der Waals' forces, and the mechanical properties of cement are affected by microand nanoscale properties of $\mathrm{C}-\mathrm{S}-\mathrm{H}$ gels $[88,89]$. Therefore, MWCNTs can be used effectively to control concrete properties, performance, and degradation processes for a superior concrete and to provide the material with new functions $[10,90]$. The following summarizes the effects of the addition of MWCNTs to cement.

4.1. Mechanical Properties. Mechanical properties of MWCNTs-reinforced cement composites are influenced by length, proportion, and dispersion method of MWCNTs. Table 2 summarizes different method and proportion used for MWCNTs dispersion in cementitious matrix and resulting improvement in strength. At present, most researchers take MWCNTs-reinforced cement paste as object of study for two major reasons: first, MWCNTs have favorable dispersibility in the matrix of cement paste with high-speed stirring and second, compared with the concrete and mortar matrix, the porosity of cement paste is lower which is advantageous in studying the enhancement mechanism of MWCNTs. As seen from Table 2, cement paste matrix tends to highlight the enhancement effect of MWCNTs.

Concerning different kinds of dispersion method and the length of MWCNTs, there is an optimal value for proportion of MWCNTs in composites. In the early studies, high content of CNTs powder (2 wt\%) was added to cement particles and dispersed by sonication in isopropanol. Although microstructure photographs reveal that CNTs can affect early-age hydration and hydration products are connected by CNTs, high amount of CNTs lead to aggregation and decrease the mechanic strength of the cementitious composites [91]. Moreover, Chaipanich et al. [92] studied the effect of adding 


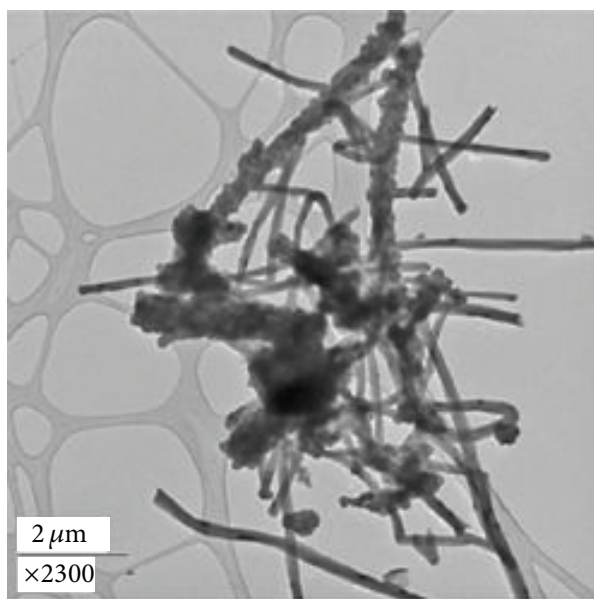

(a)

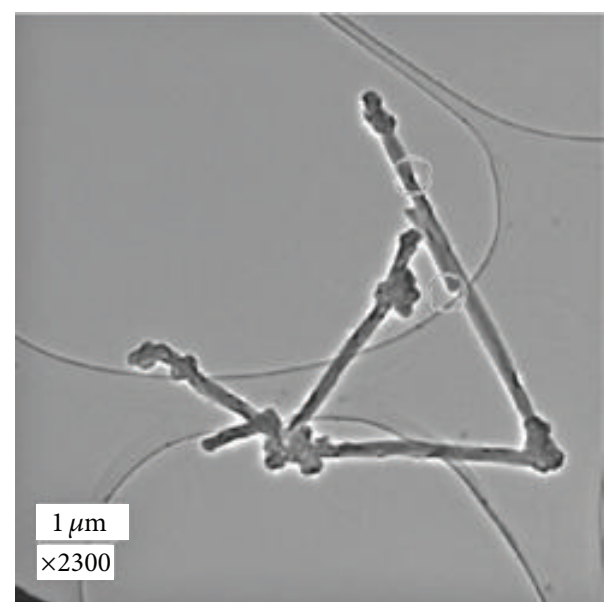

(b)

FIgURE 3: The effect of ultrasonication on dispersion of MWCNTs [80].

MWCNTs on the mechanical properties of composite, and the compressive strength of mortars with $1 \mathrm{wt} \%$ MWCNTs addition at 28 days became very close to that of the control. Agglomerates and bundles of MWCNTs lead to the formation of many defect sites in the nanocomposite [93]. Therefore, both the appropriate dispersion method and proportion of MWCNTs are very important. By using centrifugation, MWCNTs have better dispersing ability and stability [70, $73,94]$, and the flexural and compressive strength can be improved by $40 \%$ and $15 \%$, respectively, with only $0.1 \mathrm{wt} \%$ addition [73]. By adopting highly efficient surfactant, the flexural strength can even be increased by $71 \%$ [79]. KonstaGdoutos et al. studied the effect of different lengths (10$30 \mu \mathrm{m}, 10-100 \mu \mathrm{m})$ and different mixing amounts (0.048 wt\%, $0.08 \mathrm{wt} \%)$ of MWCNTs on the flexural strength of cement composites [71, 72]. As shown in Figure 4, MWCNTs appear poorly dispersed in cement paste without the use of surfactant. Figure 5(a) shows the effect of different types (short and long) of MWCNTs and concentration on the flexural strength, and the flexural strength increased by $25 \%$ with 0.08 wt $\%$ of short MWCNTs. Compared to short MWCNTs, longer MWCNTs achieve the same level of mechanical performance at lower concentrations. Similarly, Abu Al-Rub et al. investigated the effect of different concentrations of long MWCNTs (aspect ratios: 1250-3750) and short MWCNTs (aspect ratio: 157) in cement paste, and results show that low concentrations of well-dispersed MWCNTs lead to the largest enhancement [95]. However, the longer the MWCNTs are, the more difficult it is to disperse them.

Functional groups on the MWCNTs, such as carboxylic groups $(-\mathrm{COOH})$ and hydroxyl groups $(-\mathrm{OH})$, affect the mechanical behavior of cement composite. Presently, studies have shown that MWCNTs treated by $\mathrm{H}_{2} \mathrm{SO}_{4} / \mathrm{HNO}_{3}$ mixture solution lead to the formation of $-\mathrm{COOH}$ groups $[96,97]$, and the reaction scheme between carboxylated nanotube and hydrated production is shown in Figure 6. MWCNTs optimize the pore size distribution and enhance both the compressive and flexural strengths. Moreover, the treated
MWCNTs are tightly coated with C-S-H gels [66]. Another study by Habermehl-Cwirzen et al. indicated that stable and homogeneous water dispersions of MWCNTs can be obtained by using MWCNT-COOHs and the highest increase in the compressive strength is nearly $50 \%$ in cement paste incorporating only $0.045 \%$ of MWCNTs [80]. Musso et al. analyzed three different kinds of MWCNTs: pristine (asgrown), annealed, and carboxyl functionalized. The compressive strength of composites was increased by $10-20 \%$ with as-grown and annealed MWCNTs, while functionalized MWCNTs induced deterioration in the mechanical properties [75]. These results indicate that there is a chemical reaction between the MWCNT-COOHs and the $\mathrm{C}-\mathrm{S}-\mathrm{H}$ gels, which improves the load transfer between MWCNTs and cementitious matrix. It should be noted that functionalized MWCNTs could absorb water due to their hydrophilic nature. The cement paste containing carboxyl functionalized MWCNTs leads to formation of lower amount of tobermorite gel and significantly decreases the strength [75]. However, surface functionalization should be used carefully, and further research is needed to obtain more stably and uniformly MWCNTs dispersion to enhance the bond strength between MWCNTs and cement hydration products.

4.2. Young's Modulus and Porosity. Young's modulus is a measure of the stiffness of an elastic material and is a quantity used to characterize materials $[22,98]$. The space in $\mathrm{C}-\mathrm{S}-\mathrm{H}$ is called "gel porosity," and previous studies show that the additional MWCNTs can fill in the pores and lead to a denser matrix. By applying nanoindentation test, Konsta-Gdoutos et al. investigated Young's modulus of 28-day cement paste $(\mathrm{w} / \mathrm{c}=0.3)$ and cement paste reinforced with $0.025 \mathrm{wt} \%$ long, $0.048 \mathrm{wt} \%$ long, and $0.08 \mathrm{wt} \%$ short MWCNTs, as shown in Figures 5(b) and 7 [71, 72]. Cement paste reinforced with MWCNTs exhibits higher Young's modulus than plain sample in all cases, and the amount of high stiffness C$\mathrm{S}-\mathrm{H}$ is increased by the incorporation of MWCNTs. It can be deduced that MWCNTs are effective in filling the areas 
TABLE 2: Enhancement of CNTs to strength of cementitious composites.

\begin{tabular}{|c|c|c|c|c|c|}
\hline \multirow{2}{*}{ Dispersion method } & \multirow{2}{*}{ Matrix } & \multirow{2}{*}{ CNTs (wt\%) } & \multicolumn{2}{|c|}{ Strength increase (\%) } & \multirow{2}{*}{ Researcher } \\
\hline & & & Compressive & Flexural & \\
\hline $\begin{array}{l}\text { Sonication and } \\
\text { polycarboxylate }\end{array}$ & Paste & 0.2 & - & 20 & Tyson et al. [67] \\
\hline Sonication and gum arabic & Paste & 0.08 & - & 71 & Wang et al. [79] \\
\hline $\begin{array}{l}\text { Sonication, surfactant, and } \\
\text { centrifugation }\end{array}$ & Paste & 0.08 & - & 36 & Metaxa et al. [153] \\
\hline Sonication and acetone & Paste & 0.5 & 11 & - & Musso et al. [75] \\
\hline Sonication and polymers & Paste & $0.024-0.042$ & 35 & 14 & Cwirzen et al. $[80,154]$ \\
\hline Sonication & Paste & 1 & 10 & - & Nochaiya and Chaipanich [102] \\
\hline $\begin{array}{l}\text { Sulfuric and nitric acid, } \\
\text { SDS }\end{array}$ & Paste & 0.1 & 7 & - & Yu and Kwon [126] \\
\hline Sonication and surfactant & Paste & 0.5 & -8 & - & Collins et al. [77] \\
\hline Sonication and surfactant & Paste & $0.04-0.08$ & - & 25 & Konsta-Gdoutos et al. $[71,72]$ \\
\hline Sonication and stirring & Paste & 0.1 & 22 & - & Bharj et al. [155] \\
\hline $\begin{array}{l}\text { Sonication, surfactant, and } \\
\text { centrifugation }\end{array}$ & Paste & 0.1 & 15 & 40 & $\mathrm{Xu}$ et al. [73] \\
\hline $\begin{array}{l}\text { Sonication, } \mathrm{NaDDBS} \text {, and } \\
800 \mathrm{rpm} \text { stirring }\end{array}$ & Paste & 0.5 & 15 & - & Zuo et al. [156] \\
\hline Silica fume & Paste & 0.15 & 30 & - & Kim et al. [157] \\
\hline $\begin{array}{l}\text { Sonication and } \\
\text { superplasticizer }\end{array}$ & Paste & 0.1 & - & 60 & Abu Al-Rub et al. [95] \\
\hline $\begin{array}{l}\text { Ultrasonication and } \\
\text { superficial active agents }\end{array}$ & Paste & 0.2 & 29.5 & 34.5 & Luo et al. [78] \\
\hline Sulfuric and mixed acid & Mortar & 0.5 & 19 & 25 & Li et al. [66] \\
\hline Sonication and surfactant & Mortar & 0.02 & 15.9 & 20.7 & Xu et al. [94] \\
\hline Sonication and SDBS & Mortar & 0.08 & 18 & 19 & Liu et al. [158] \\
\hline Polycarboxylate & Mortar & 0.3 & 12 & - & Melo et al. [76] \\
\hline Conventional stirring & Mortar & 0.01 & 10 & 24 & Hamzaoui et al. [159] \\
\hline Sonication and gum arabic & Mortar & 0.08 & 20 & 38.5 & Wang et al. [160] \\
\hline Dry mixing & Mortar & 0.02 & 11 & - & Morsy et al. [161] \\
\hline No information & Concrete & 0.05 & 65 & - & Yakovlev et al. [162] \\
\hline Sonication & Concrete & 0.02 & 2 & - & Wille and Loh [163] \\
\hline $\begin{array}{l}\text { Sonication and chemical } \\
\text { treatments }\end{array}$ & Concrete & 1.25 & 72 & - & Wang et al. [164] \\
\hline Stirring $350 \mathrm{rpm}$ & Concrete & 0.02 & 24 & 24 & Keriené et al. [165] \\
\hline
\end{tabular}

in $\mathrm{C}-\mathrm{S}-\mathrm{H}[24,99]$. Recently, three-point flexural bending tests were performed to evaluate Young's modulus of the cement/CNTs composites at ages of 7, 14, and 28 days, and Young's modulus increased as the short-MWCNTs' concentration is increasing; moreover, low concentrations of longMWCNTs could lead to a much higher increase in Young's modulus as compared to higher concentrations of short MWCNTs [95].

Mercury intrusion porosimetry (MIP) has been widely used to characterize the distribution of pore size in cementbased materials and determine the quality of concrete material $[100,101]$. Pores can be classified into two groups depending on size distribution: macropores ( $d \geq 50 \mathrm{~nm}$ ) and mesopores $(d<50 \mathrm{~nm})$. The pore size tends to reduce with increasing MWCNTs content, with the number of pores larger than $50 \mathrm{~nm}$ reducing significantly [73]. Another study also revealed that the total porosity of the mixes with MWCNTs is found to decrease with increasing CNTs content, as shown in Figure 8. Moreover, the addition of MWCNTs at $1 \mathrm{wt} \%$ was found to result in the lowest total intruded volume $\left(0.1422 \mathrm{~cm}^{3} / \mathrm{g}\right)$ compared to the plain cement paste $\left(0.1717 \mathrm{~cm}^{3} / \mathrm{g}\right)[102]$. According to Li et al., when containing $0.5 \%$ CNTs, PCNT (cement mortar containing treated CNTs) has a total porosity of $10.8 \%$, about $64 \%$ lower than that of 

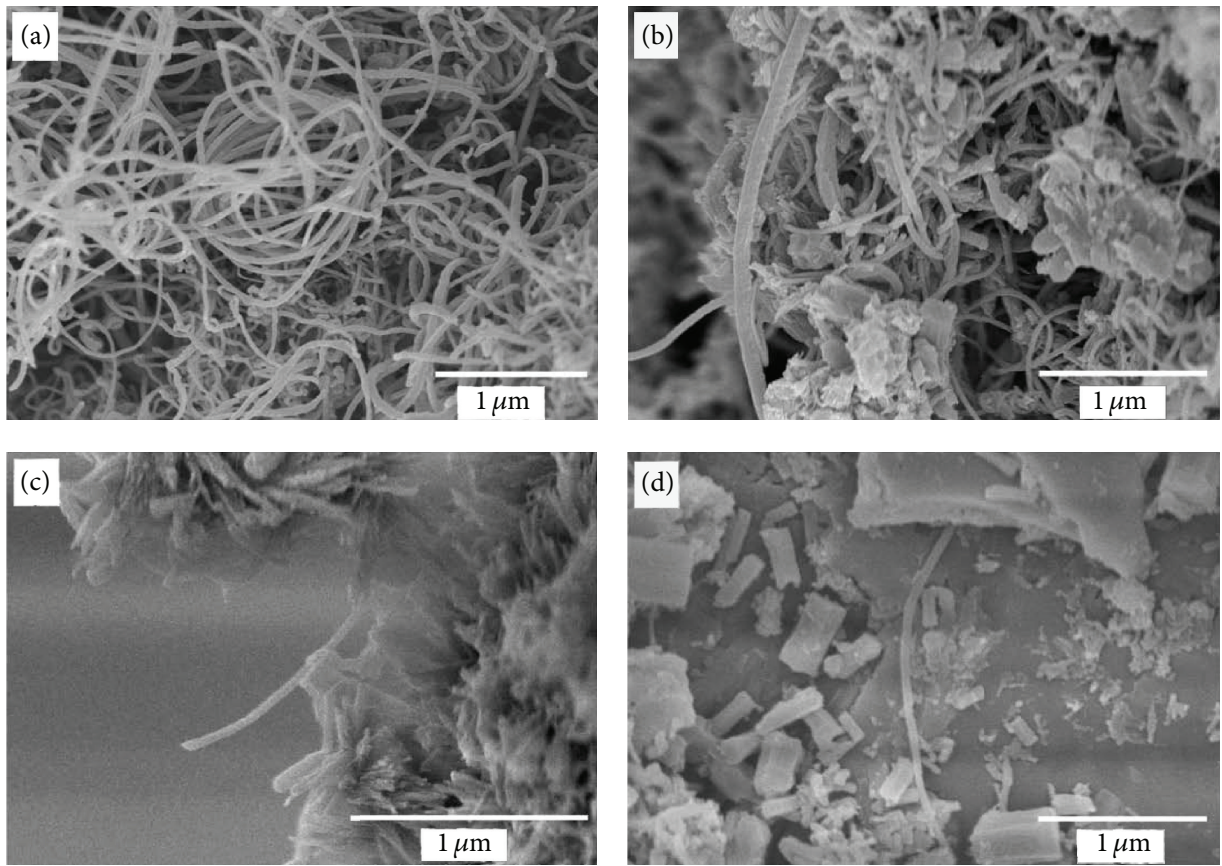

FIGURE 4: Surfactant concentration effect on CNTs dispersion: (a)-(d) represent a dispersant to MWCNT weight ratio of 0, 1.5, 4.0, and 6.25, respectively [72].

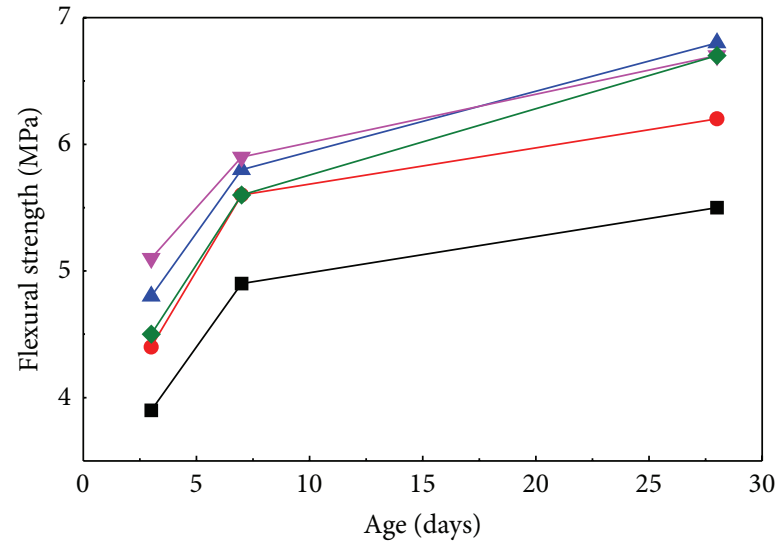

$\begin{array}{ll}\rightarrow-\text { CP } & \checkmark \text { Short MWCNTs } 0.08 \mathrm{wt} \% \\ \rightarrow-\text { Short MWCNTs } 0.048 \mathrm{wt} \% & -\checkmark \text { Long MWCNTs } 0.08 \mathrm{wt} \% \\ \simeq \text { Long MWCNTs } 0.048 \mathrm{wt} \% & \end{array}$

(a)
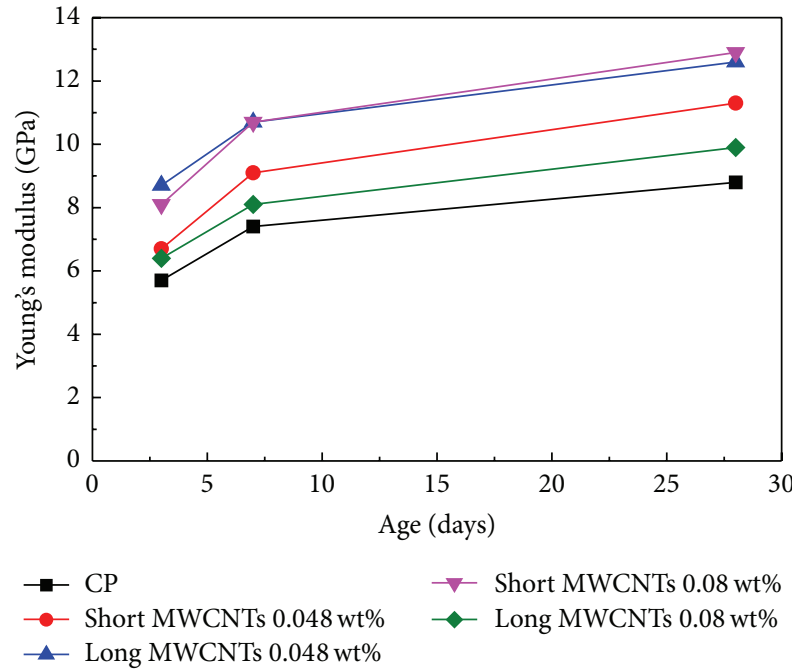

(b)

FIGURE 5: Effect of different types (short and long) of MWCNTs and concentration on the flexural strength (a) and Young's modulus of cement paste (b) [72].

PCC (control Portland cement composites); moreover, the pores with a size $d \geq 50 \mathrm{~nm}$ in PCNT are $1.47 \%$, about $82 \%$ lower than that of PCC [66].

4.3. Enhancement Mechanism. CNTs are expected to resolve the brittleness problem when they are added into the composites [103-106]. The features of fracture mechanics of ceramic-matrix composites are similar to those of the cement-based material that provided new insight into the fracture mechanisms for MWCNTs-cement composites. Earlier studies have found that the bending strength and fracture toughness of the $\mathrm{SiC}$ ceramic are increased by the introduction of CNTs [107-109], and three hallmarks of toughening are found in micron-scale fiber composites: crack deflection at the CNT-matrix interface, crack bridging by CNTs, and CNT pullout on the fracture surfaces $[110,111]$. For CNTs-cement composites, the enhancement of mechanical properties achieved has been found to be much higher than 

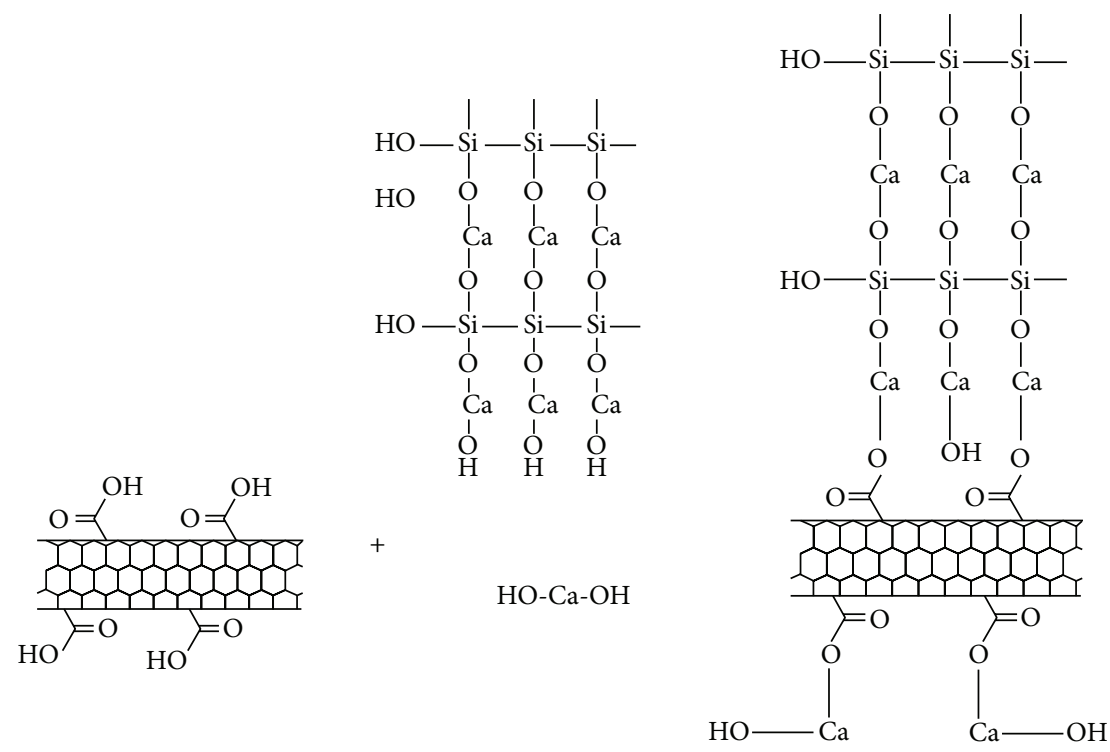

FIGURE 6: Reaction scheme between carboxylated nanotube and hydrated production of cement [66].

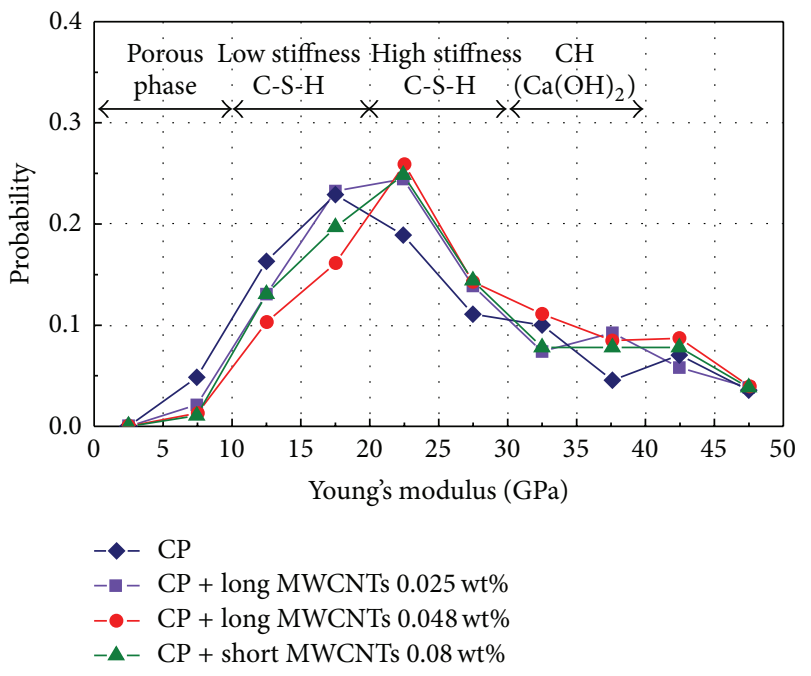

FIGURE 7: Probability pots of Young's modulus of cement paste reinforced with CNTs [71].

that predicted using theoretical equations [72]. Here, we will discuss the related mechanism from the following aspects.

The first aspect is the network structure of MWCNTs in the matrix. Compared with short MWCNTs, long MWCNTs can provide the similar mechanical properties even at very low concentrations due to network effect. If MWCNTs are uniformly distributed in the matrix, MWCNTs will form an intertwined mesh distribution and the hydration products will be connected as a whole [112], as shown in Figure 9. The formation of homogeneous network of MWCNTs fillers throughout the matrix is one of the most important factors to improve the macroperformances of the composite [78].

The second aspect is the nucleation effect of MWCNTs. MWCNTs can act as nuclei for cement hydration due to their high surface energy, and the hydration products of cement are attracted to grow around the MWCNTs. So the existence of the MWCNTs affects the chemical reaction of the hydrated cement, which improve the cement matrix by increasing the amount of high stiffness $\mathrm{C}-\mathrm{S}-\mathrm{H}$ [72]. Moreover, the addition of MWCNTs fills the voids between the larger cement particles and decreases the porosity of cement composites. In particular, MWCNTs refine the pore size distribution by reducing the amount of harmful pores that is defined as pore sizes greater than $50 \mathrm{~nm}$ in diameter. It is also observed that even when MWCNTs are poorly dispersed, they can also prevent the formation of shrinkage cracks and improve the mechanical performance [68].

Finally, crack bridging of MWCNTs is the main reason for the enhancement of cement matrix toughness. Similarly, uniformly dispersed MWCNTs contribute to effectively and homogeneously dissipating the fracture energy by crack deflection and frictional pullout from the alumina ceramic $[113,114]$. Pullout of inner wall from outer walls of the fractured MWCNTs showed contribution of even inner walls to carrying the load. Pullout tests reveal that the MWCNTs, rather than pulling out from the alumina matrix, broke in the outer shells and then the inner core is pulled away, leaving fragments of the outer shells in the matrix [115]. The TEM images (Figure 10(a)) show clear embedment of MWCNTs within the cement hydration products and bridging of neighboring hydration products by long MWCNTs [95]. The tensile strength of MWCNTs is much higher than that of cement matrix. Therefore, MWCNTs will be pulled out inevitably when a crack develops to a certain degree.

Interfacial sliding also plays a key role in determining the strength and toughness of brittle composites [116-119]. If the load bearing ability of MWCNTs is possibly reduced during the processing, the MWCNTs will act as a defect and thus lower the mechanical properties even if they are uniformly dispersed within the matrix with intimate interfaces [120]. 


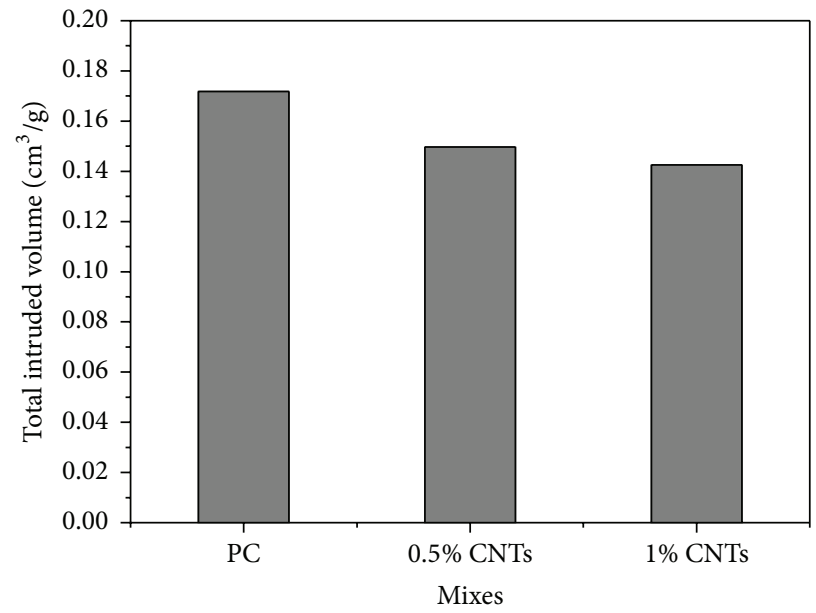

(a)

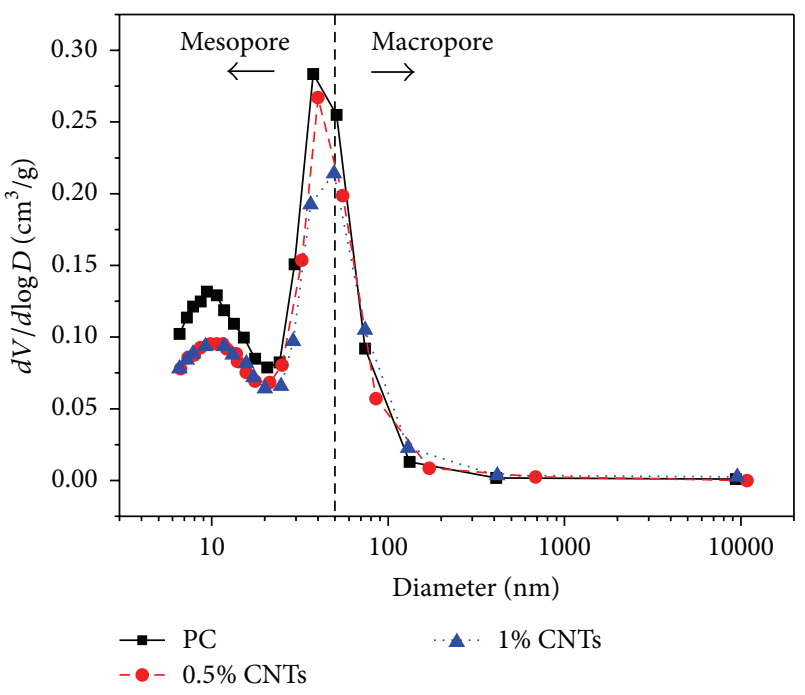

(b)

FIGURE 8: MIP analyses of CNTs-cement pastes: (a) total pore volume and (b) pore size distribution [102].

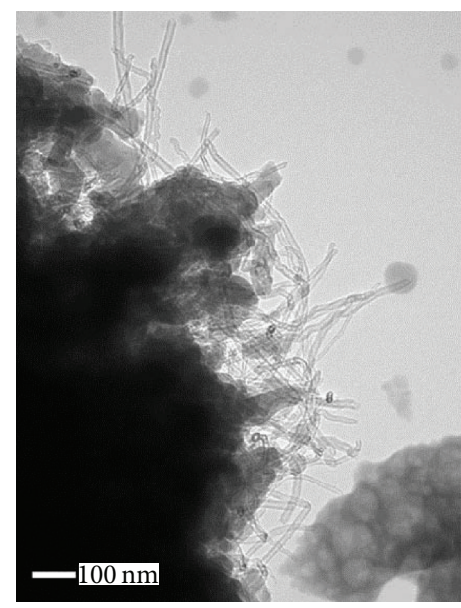

(a)

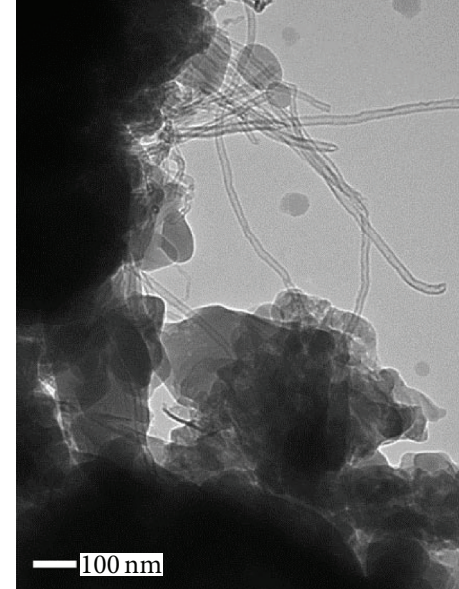

(b)

FIgURE 9: TEM images of short MWCNTs (a) and long MWCNTs (b) within the hardened cement paste [95].

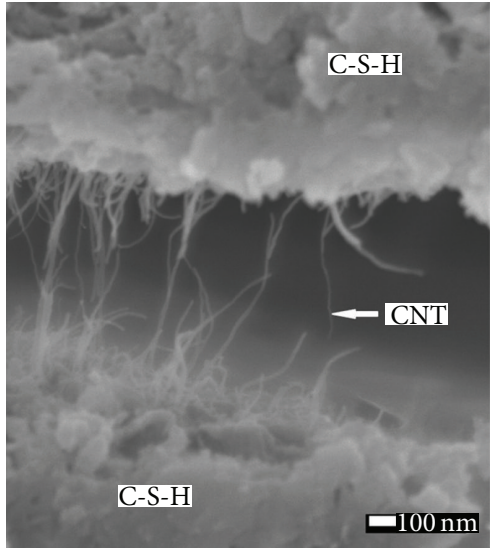

(a)

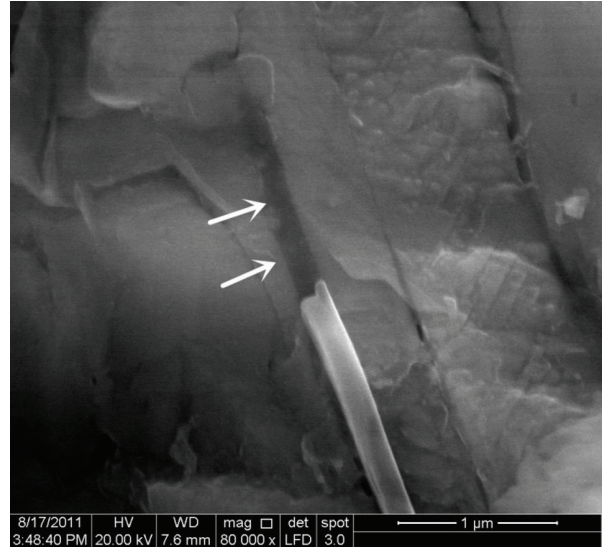

(b)

FIGURE 10: The microcrack bridging (a) [76] and breakage (b) [73] of the MWCNTs in the cement paste. 
According to a study by Wang et al. [121], pullout of MWCNTs at interfaces was efficient in transferring the load from the mullite matrix to nanotubes. Furthermore, Pavia and Curtin [117] studied the interface behavior during nanotube pullout by using molecular dynamics models. The effective friction stresses were quite high for interstitial areal densities of $0.72-$ $2.18 \mathrm{~nm}^{-2}$, and "friction-like" behavior could emerge from nonsmooth interfaces. However, understanding the reinforcing ability of MWCNTs embedded in the ceramic matrix would greatly help to study the mechanism of MWCNTs in a cement material. MWCNTs with higher aspect ratios are more effective reinforcements if well dispersed. As shown in Figure 10(b), a CNT slips in the cement matrix and the groove can be seen clearly. The interaction leads to a strong covalent force on the interface between the reinforcement and matrix in the composites and therefore increases the load-transfer efficiency from cement matrix to MWCNTs [122].

\section{Piezoresistive Properties}

The special semiconductive electrical and metallic properties of MWCNTs are much different from those of traditional fiber, and these excellent properties represent a potential for investigating the piezoresistive properties of MWCNTscement composite $[123,124]$. Li et al. developed piezoresistive MWCNTs-cement composites and measured the piezoresistivity of these composites under uniaxial compression [125]. According to $\mathrm{Yu}$ and Kwon, the electrical resistance of the MWCNTs-cement composite changed with the compressive stress level, which indicated the possibility of using the MWCNTs-cement composite as a stress sensor for civil structures [126]. Han et al. investigated the effect of water content on the piezoresistivity of MWNTs-cement composites, and experimental results indicated that the piezoresistive sensitivities of MWNTs-cement composites with $0.1,3.3,7.6$, and $9.9 \%$ of water content were $0.60,0.73,0.34$, and $0.06 \mathrm{k} \Omega / \mathrm{MPa}$, respectively [127]. They also investigated the effects of MWCNTs concentration level on the piezoresistivity of MWCNTscement composites. The results showed that the piezoresistive sensitivities of MWCNTs-cement composites with 0.05, 0.1, and $1.0 \mathrm{wt} \%$ of MWNTs first increase and then decrease with the increase of CNT concentration levels [128].

\section{Large-Scale Production}

MWCNTs have built broad interest in most areas of engineering, and chemical vapor deposition (CVD) has been widely used to synthesize MWCNTs because of the flexible control of reaction parameters $[129,130]$. However, a wide compatibility and a high rate of performance to price are key determining factors in whether or not MWCNTs will be used. In order to achieve low cost and mass production of MWCNTs, several methods have been reported, and the improvements in manufacturing MWCNTs have also been matched by significant price reductions. Qiu et al. [131] reported that the synthesis of MWCNTs could be produced by one-step annealing of polyacrylonitrile microspheres (PANMSs) at low temperature $\left(1000^{\circ} \mathrm{C}\right)$. This method can produce MWCNTs in large-scale quantity because PANMSs can be prepared in large-scale quantity at low cost production. In another study, MWCNTs were effectively synthesized by arc discharge process with iron as a catalyst and sulfur as a promoter, and this approach presented an effective, low-cost synthesis of MWCNTs using low-pressure flowing air as buffer gas [132]. Although many problems about industrialization of CNTs need to be solved, the development of synthesis routes for the large-scale mass production of MWCNTs is highly desirable.

\section{Toxicity and Environmental Impact}

The peculiar toxicity associated with nanomaterials that are different from bulk materials of the same chemical composition has been a concern [133]. In particular, MWCNTs with a high aspect ratio have also attracted notoriety for their possible environmental and health effects [134]. As colloids in water, MWCNTs can be easily transported to virtually anywhere on the earth. When the surface properties of MWCNTs change, their ability to bind heavy metals increases. Experimental results indicated that MWCNTs settle more rapidly than carbon black and activate carbon particles, suggesting sediment as the ultimate repository. The presence of functional groups slows the settling of MWCNTs, especially in combination with natural organic matter [135]. Schierz and Zänker studied the behavior of MWCNTs as potential carriers of pollutants in the case of accidental MWCNT release to the environment, and results showed that transport of heavy metals (uranium) bound to MWCNTs through natural aquatic systems and even into biological systems is at least conceivable [136]. Thus, understanding the fate of CNTs in the natural environment is very important to humans [137].

After 2008, the number of reports on the toxicity of MWCNTs increased, as they were industrially useful. However, the toxicity of MWCNTs is a very complicated issue, and the variation in shape, dimensions, and surface conditions of MWCNTs affects their effect on the cells. Some studies have shown that purified and surface oxidized MWCNTs with acid treatment suppress cell viability, and MWCNTs with smaller diameters show less cytotoxicity [138-140]. Many studies also found that MWCNTs have toxicity similar to or higher than asbestos because of their similarity in shapes $[141,142]$. Poland et al. [143] reported the effect of fiber length on toxicity, and the results indicated that long MWCNTs and amosite induce inflammation and granulomas in the abdominal cavity. Although further research is required, the available data suggest that, under certain conditions, MWCNTs can pose a serious risk to human health [144]. Therefore, people should avoid direct contact with CNTs during processing, and it is essential for proper development of regulations for the use of CNTs.

\section{Summary and Conclusion}

With excellent properties, MWCNTs have enormous development potentials in the field of construction. In this review, the literatures on MWCNTs reinforced cement composites 
are comprehensively reviewed, and the effects of MWCNTs on the cement-based material were summarized.

The extraordinary strength, Young's modulus, and unique chemical properties of MWCNTs have stimulated extensive research activities across the world since their discovery. MWCNTs composite systems are being investigated in the fields of metal, polymer, and ceramic, so MWCNTs can play a significant role in improving the strength, fracture toughness, Young's modulus, and porosity of cementitious materials.

Dispersion of MWCNTs into cementitious composites is a major issue. MWCNTs are prone to reunite and form MWCNT bundle structures because of high surface energy. Although various dispersing methods are in action, the combination of ultrasonication and surface modification of MWCNTs appears as the most promising method. The dispersion mechanism of MWCNTs still needs to be studied in further researches.

MWCNTs affect the hydration process of cement by providing attachment sites for the $\mathrm{C}-\mathrm{S}-\mathrm{H}$ gels which acts as filler resulting in a higher strength and denser microstructure of matrix. The strengths are found to be increased with the inclusion of MWCNTs, and they are influenced by the type, length, and concentration of MWCNTs. In addition, good interaction between MWCNTs and the cement hydration productions has been observed. Debonding and crack bridging of MWCNTs are the main reason for the enhancement of matrix toughness.

\section{Conflict of Interests}

The authors declare that there is no conflict of interests regarding the publication of this paper.

\section{Acknowledgments}

This study was supported by National Key Technology Research and Development Program of the Ministry of Science and Technology of China (no. 2012BAJ13B04).

\section{References}

[1] B. Han, S. Sun, S. Ding, L. Zhang, X. Yu, and J. Ou, "Review of nanocarbon-engineered multifunctional cementitious composites," Composites Part A: Applied Science and Manufacturing, vol. 70, pp. 69-81, 2015.

[2] A. M. Alhozaimy, P. Soroushian, and F. Mirza, "Mechanical properties of polypropylene fiber reinforced concrete and the effects of pozzolanic materials," Cement and Concrete Composites, vol. 18, no. 2, pp. 85-92, 1996.

[3] S. P. Shah and C. Ouyang, "Mechanical behavior of fiberreinforced cement-based composites," Journal of the American Ceramic Society, vol. 74, no. 11, pp. 2727-2953, 1991.

[4] A. M. Neville and J. J. Brooks, Concrete Technology, Longman Scientific \& Technical, Harlow, UK, 1987.

[5] S. Xu and Q. Li, "Theoretical analysis on bending behavior of functionally graded composite beam crack-controlled by ultrahigh toughness cementitious composites," Science in China, Series E: Technological Sciences, vol. 52, no. 2, pp. 363-378, 2009.
[6] V. C. Li and C. K. Leung, "Theory of steady state and multiple cracking of random discontinuous fiber reinforced brittle matrix composites," Journal of Engineering Mechanics, vol. 118, pp. 2246-2264, 1992.

[7] A. M. Okeil, S. El-Tawil, and M. Shahawy, "Short-term tensile strength of carbon fiber-reinforced polymer laminates for flexural strengthening of concrete girders," ACI Structural Journal, vol. 98, no. 4, pp. 470-478, 2001.

[8] T. Y. Lim, P. Paramasivam, and S. L. Lee, "Analytical model for tensile behavior of steel-fiber concrete," ACI Materials Journal, vol. 84, no. 4, pp. 286-298, 1987.

[9] C. Zweben, “Tensile failure of fiber composites," AIAA Journal, vol. 6 , no. 12, pp. 2325-2331, 1968.

[10] F. Sanchez and K. Sobolev, "Nanotechnology in concrete-a review," Construction and Building Materials, vol. 24, no. 11, pp. 2060-2071, 2010.

[11] H. Li, H.-G. Xiao, J. Yuan, and J. Ou, "Microstructure of cement mortar with nano-particles," Composites Part B: Engineering, vol. 35, no. 2, pp. 185-189, 2004.

[12] B.-W. Jo, C.-H. Kim, G.-H. Tae, and J.-B. Park, "Characteristics of cement mortar with nano- $\mathrm{SiO}_{2}$ particles," Construction and Building Materials, vol. 21, no. 6, pp. 1351-1355, 2007.

[13] L. P. Singh, S. R. Karade, S. K. Bhattacharyya, M. M. Yousuf, and S. Ahalawat, "Beneficial role of nanosilica in cement based materials-a review," Construction and Building Materials, vol. 47, pp. 1069-1077, 2013.

[14] S. Iijima, "Helical microtubules of graphitic carbon," Nature, vol. 354, no. 6348, pp. 56-58, 1991.

[15] A. Jorio, G. Dresselhaus, and M. S. Dresselhaus, Carbon Nanotubes: Advanced Topics in the Synthesis, Structure, Properties And Applications, Springer Science \& Business Media, 2007.

[16] S. Reich, C. Thomsen, and J. Maultzsch, Carbon Nanotubes: Basic Concepts and Physical Properties, John Wiley \& Sons, New York, NY, USA, 2008.

[17] V. N. Popov, "Carbon nanotubes: properties and application," Materials Science and Engineering R: Reports, vol. 43, no. 3, pp. 61-102, 2004.

[18] J. Grávalos, J. M. Mieres, S. González, Y. de Miguel, A. Porro, and P. Bartos, "A new generation of construction materials: carbon nanotubes incorporated to concrete and polymeric matrix," in NICOM 2: 2nd International Symposium on Nanotechnology in Construction, pp. 215-221, RILEM Publications SARL, 2006.

[19] X. J. Xiang, T. L. Torwald, T. Staedler, and R. H. Trettin, "Carbon nanotubes as a new reinforcement material for modern cementbased binders," in NICOM 2: 2nd International Symposium on Nanotechnology in Construction, pp. 209-213, RILEM Publications SARL, 2006.

[20] T. H. Wegner, J. E. Winandy, and M. A. Ritter, "Nanotechnology opportunities in residential and non-residential construction," in Proceedings of the 2nd International Symposium on Nanotechnology in Construction, Bilbao, Spain, 2005.

[21] J. Lee, S. Mahendra, and P. J. J. Alvarez, "Nanomaterials in the construction industry: a review of their applications and environmental health and safety considerations," ACS Nano, vol. 4, no. 7, pp. 3580-3590, 2010.

[22] R. Siddique and A. Mehta, "Effect of carbon nanotubes on properties of cement mortars," Construction and Building Materials, vol. 50, pp. 116-129, 2014.

[23] P. Wang, H. Xu, R. Chen, J. Xu, and X. Zeng, "Experimental research on compression properties of cement asphalt mortar due to drying and wetting cycle," Advances in Materials Science and Engineering, vol. 2014, Article ID 769248, 6 pages, 2014. 
[24] S. Chuah, Z. Pan, J. G. Sanjayan, C. M. Wang, and W. H. Duan, "Nano reinforced cement and concrete composites and new perspective from graphene oxide," Construction and Building Materials, vol. 73, pp. 113-124, 2014.

[25] M. J. Hanus and A. T. Harris, "Nanotechnology innovations for the construction industry," Progress in Materials Science, vol. 58, no. 7, pp. 1056-1102, 2013.

[26] M.-F. Yu, O. Lourie, M. J. Dyer, K. Moloni, T. F. Kelly, and R. S. Ruoff, "Strength and breaking mechanism of multiwalled carbon nanotubes under tensile load," Science, vol. 287, no. 5453, pp. 637-640, 2000.

[27] T. Filleter, R. Bernal, S. Li, and H. D. Espinosa, "Ultrahigh strength and stiffness in cross-linked hierarchical carbon nanotube bundles," Advanced Materials, vol. 23, no. 25, pp. 28552860, 2011.

[28] B. Peng, M. Locascio, P. Zapol et al., "Measurements of near-ultimate strength for multiwalled carbon nanotubes and irradiation-induced crosslinking improvements," Nature Nanotechnology, vol. 3, no. 10, pp. 626-631, 2008.

[29] M. Delmas, M. Pinault, S. Patel, D. Porterat, C. Reynaud, and M. Mayne-Lhermite, "Growth of long and aligned multiwalled carbon nanotubes on carbon and metal substrates," Nanotechnology, vol. 23, no. 10, Article ID 105604, 2012.

[30] W. Cho, M. Schulz, and V. Shanov, "Growth termination mechanism of vertically aligned centimeter long carbon nanotube arrays," Carbon, vol. 69, pp. 609-620, 2014.

[31] Y. Zhao, Y. Hu, Y. Li et al., "Super-long aligned $\mathrm{TiO}_{2} /$ carbon nanotube arrays," Nanotechnology, vol. 21, no. 50, Article ID 505702, 2010.

[32] S. Chakrabarti, K. Gong, and L. Dai, "Structural evaluation along the nanotube length for super-long vertically aligned double-walled carbon nanotube arrays," The Journal of Physical Chemistry C, vol. 112, no. 22, pp. 8136-8139, 2008.

[33] S. H. Kim, G. W. Mulholland, and M. R. Zachariah, "Density measurement of size selected multiwalled carbon nanotubes by mobility-mass characterization," Carbon, vol. 47, no. 5, pp. 12971302, 2009.

[34] C. Laurent, E. Flahaut, and A. Peigney, "The weight and density of carbon nanotubes versus the number of walls and diameter," Carbon, vol. 48, no. 10, pp. 2994-2996, 2010.

[35] K. Dasgupta, J. B. Joshi, and S. Banerjee, "Fluidized bed synthesis of carbon nanotubes-a review," Chemical Engineering Journal, vol. 171, no. 3, pp. 841-869, 2011.

[36] N. Chiodarelli, O. Richard, H. Bender et al., "Correlation between number of walls and diameter in multiwall carbon nanotubes grown by chemical vapor deposition," Carbon, vol. 50, no. 5, pp. 1748-1752, 2012.

[37] R. R. Bacsa, C. Laurent, A. Peigney, W. S. Bacsa, T. Vaugien, and A. Rousset, "High specific surface area carbon nanotubes from catalytic chemical vapor deposition process," Chemical Physics Letters, vol. 323, no. 5-6, pp. 566-571, 2000.

[38] A. Peigney, C. Laurent, E. Flahaut, R. R. Bacsa, and A. Rousset, "Specific surface area of carbon nanotubes and bundles of carbon nanotubes," Carbon, vol. 39, no. 4, pp. 507-514, 2001.

[39] A. J. Stone and D. J. Wales, "Theoretical studies of icosahedral $\mathrm{C}_{60}$ and some related species," Chemical Physics Letters, vol. 128, no. 5-6, pp. 501-503, 1986.

[40] B. I. Yakobson, "Mechanical relaxation and intramolecular plasticity' in carbon nanotubes," Applied Physics Letters, vol. 72, no. 8, pp. 918-920, 1998.
[41] N. Chandra, S. Namilae, and C. Shet, "Local elastic properties of carbon nanotubes in the presence of Stone-Wales defects," Physical Review B, vol. 69, no. 9, Article ID 094101, 2004.

[42] J. Song, H. Jiang, D.-L. Shi et al., "Stone-Wales transformation: precursor of fracture in carbon nanotubes," International Journal of Mechanical Sciences, vol. 48, no. 12, pp. 1464-1470, 2006.

[43] N. M. Pugno, "Young's modulus reduction of defective nanotubes," Applied Physics Letters, vol. 90, no. 4, Article ID 043106, 2007.

[44] N. M. Pugno and R. S. Ruoff, "Quantized fracture mechanics," Philosophical Magazine, vol. 84, no. 27, pp. 2829-2845, 2004.

[45] S. L. Mielke, D. Troya, S. Zhang et al., "The role of vacancy defects and holes in the fracture of carbon nanotubes," Chemical Physics Letters, vol. 390, no. 4-6, pp. 413-420, 2004.

[46] J. Liu, A. G. Rinzler, H. Dai et al., "Fullerene pipes," Science, vol. 280, no. 5367, pp. 1253-1256, 1998.

[47] W. Shao, Q. Wang, F. Wang, and Y. Chen, "The cutting of multiwalled carbon nanotubes and their strong interfacial interaction with polyamide 6 in the solid state," Carbon, vol. 44, no. 13, pp. 2708-2714, 2006.

[48] N. Pierard, A. Fonseca, Z. Konya, I. Willems, G. Van Tendeloo, and J. B. Nagy, "Production of short carbon nanotubes with open tips by ball milling," Chemical Physics Letters, vol. 335, no. 1-2, pp. 1-8, 2001.

[49] M. Q. Tran, C. Tridech, A. Alfrey, A. Bismarck, and M. S. P. Shaffer, "Thermal oxidative cutting of multi-walled carbon nanotubes," Carbon, vol. 45, no. 12, pp. 2341-2350, 2007.

[50] X. X. Wang and J. N. Wang, "Preparation of short and waterdispersible carbon nanotubes by solid-state cutting," Carbon, vol. 46, no. 1, pp. 117-125, 2008.

[51] L. Chen, X.-J. Pang, Q.-T. Zhang, and Z.-L. Yu, "Cutting of carbon nanotubes by a two-roller mill," Materials Letters, vol. 60, no. 2, pp. 241-244, 2006.

[52] S.-H. Jeong, O.-J. Lee, K.-H. Lee, S. H. Oh, and C.-G. Park, "Preparation of aligned carbon nanotubes with prescribed dimensions: template synthesis and sonication cutting approach," Chemistry of Materials, vol. 14, no. 4, pp. 1859-1862, 2002.

[53] P. Garcés, J. Carmona, O. Galao, E. Zornoza, and M. A. Climent, "Carbon nanofibre cement paste as anode for electrochemical chloride removal," in NICOM4 Nanotechnology in Construction, Proceedings of the 4th International Symposium on Nanotechnology in Construction, 2012.

[54] B. Q. Wei, R. Vajtai, and P. M. Ajayan, "Reliability and current carrying capacity of carbon nanotubes," Applied Physics Letters, vol. 79, no. 8, pp. 1172-1174, 2001.

[55] P. J. De Pablo, E. Graugnard, B. Walsh, R. P. Andres, S. Datta, and R. Reifenberger, "A simple, reliable technique for making electrical contact to multiwalled carbon nanotubes," Applied Physics Letters, vol. 74, no. 2, pp. 323-325, 1999.

[56] T. Dürkop, B. M. Kim, and M. S. Fuhrer, "Properties and applications of high-mobility semiconducting nanotubes," Journal of Physics Condensed Matter, vol. 16, no. 18, pp. R553-R580, 2004.

[57] K. Gopalakrishnan, B. Birgisson, P. Taylor, and N. O. AttohOkine, Nanotechnology in Civil Infrastructure, Springer, Berlin, Germany, 2011.

[58] A. Yazdanbakhsh, Z. C. Grasley, B. Tyson, and R. A. Al-Rub, "Carbon nano filaments in cementitious materials: some issues on dispersion and interfacial bond," ACI Special Publication, vol. 267, pp. 31-34, 2009. 
[59] F. D. P. Cota, T. H. Panzera, M. A. Schiavon et al., "Full factorial design analysis of carbon nanotube polymer-cement composites," Materials Research, vol. 15, no. 4, pp. 573-580, 2012.

[60] P.-C. Ma, N. A. Siddiqui, G. Marom, and J.-K. Kim, "Dispersion and functionalization of carbon nanotubes for polymer-based nanocomposites: a review," Composites Part A: Applied Science and Manufacturing, vol. 41, no. 10, pp. 1345-1367, 2010.

[61] I. Rhee and Y.-S. Roh, "Properties of normal-strength concrete and mortar with multi-walled carbon nanotubes," Magazine of Concrete Research, vol. 65, no. 16, pp. 951-961, 2013.

[62] Y. B. Li, B. Q. Wei, J. Liang, Q. Yu, and D. H. Wu, "Transformation of carbon nanotubes to nanoparticles by ball milling process," Carbon, vol. 37, no. 3, pp. 493-497, 1999.

[63] Y. Wang, J. Wu, and F. Wei, "A treatment method to give separated multi-walled carbon nanotubes with high purity, high crystallization and a large aspect ratio," Carbon, vol. 41, no. 15, pp. 2939-2948, 2003.

[64] P. Garg, J. L. Alvarado, C. Marsh, T. A. Carlson, D. A. Kessler, and K. Annamalai, "An experimental study on the effect of ultrasonication on viscosity and heat transfer performance of multiwall carbon nanotube-based aqueous nanofluids," International Journal of Heat and Mass Transfer, vol. 52, no. 21-22, pp. 50905101, 2009.

[65] A. Sobolkina, V. Mechtcherine, V. Khavrus et al., "Dispersion of carbon nanotubes and its influence on the mechanical properties of the cement matrix," Cement and Concrete Composites, vol. 34, no. 10, pp. 1104-1113, 2012.

[66] G. Y. Li, P. M. Wang, and X. Zhao, "Mechanical behavior and microstructure of cement composites incorporating surfacetreated multi-walled carbon nanotubes," Carbon, vol. 43, no. 6 , pp. 1239-1245, 2005.

[67] B. M. Tyson, R. K. Abu Al-Rub, A. Yazdanbakhsh, and Z. Grasley, "Carbon nanotubes and carbon nanofibers for enhancing the mechanical properties of nanocomposite cementitious materials," Journal of Materials in Civil Engineering, vol. 23, no. 7, pp. 1028-1035, 2011.

[68] A. Yazdanbakhsh, Z. Grasley, B. Tyson, and R. K. Abu AlRub, "Distribution of carbon nanofibers and nanotubes in cementitious composites," Transportation Research Record, vol. 2142, pp. 89-95, 2010.

[69] I. Campillo, J. S. Dolado, and A. Porro, High-Performance Nanostructured Materials for Construction, vol. 292, Royal Society of Chemistry, 2004.

[70] Z. S. Metaxa, M. S. Konsta-Gdoutos, and S. P. Shah, "Carbon nanofiber cementitious composites: effect of debulking procedure on dispersion and reinforcing efficiency," Cement and Concrete Composites, vol. 36, no. 1, pp. 25-32, 2013.

[71] M. S. Konsta-Gdoutos, Z. S. Metaxa, and S. P. Shah, "Multiscale mechanical and fracture characteristics and early-age strain capacity of high performance carbon nanotube/cement nanocomposites," Cement and Concrete Composites, vol. 32, no. 2, pp. 110-115, 2010.

[72] M. S. Konsta-Gdoutos, Z. S. Metaxa, and S. P. Shah, "Highly dispersed carbon nanotube reinforced cement based materials," Cement and Concrete Research, vol. 40, no. 7, pp. 1052-1059, 2010.

[73] S. Xu, J. Liu, and Q. Li, "Mechanical properties and microstructure of multi-walled carbon nanotube-reinforced cement paste," Construction and Building Materials, vol. 76, pp. 16-23, 2015.

[74] L. I. Nasibulina, I. V. Anoshkin, A. G. Nasibulin, A. Cwirzen, V. Penttala, and E. I. Kauppinen, "Effect of carbon nanotube aqueous dispersion quality on mechanical properties of cement composite," Journal of Nanomaterials, vol. 2012, Article ID 169262, 6 pages, 2012.

[75] S. Musso, J.-M. Tulliani, G. Ferro, and A. Tagliaferro, "Influence of carbon nanotubes structure on the mechanical behavior of cement composites," Composites Science and Technology, vol. 69, no. 11-12, pp. 1985-1990, 2009.

[76] V. S. Melo, J. M. F. Calixto, L. O. Ladeira, and A. P. Silva, "Macroand micro-characterization of mortars produced with carbon nanotubes," ACI Materials Journal, vol. 108, no. 3, pp. 327-332, 2011.

[77] F. Collins, J. Lambert, and W. H. Duan, "The influences of admixtures on the dispersion, workability, and strength of carbon nanotube-OPC paste mixtures," Cement and Concrete Composites, vol. 34, no. 2, pp. 201-207, 2012.

[78] J. Luo, Z. Duan, and H. Li, "The influence of surfactants on the processing of multi-walled carbon nanotubes in reinforced cement matrix composites," Physica Status Solidi AApplications and Materials Science, vol. 206, no. 12, pp. 27832790, 2009.

[79] B. Wang, Y. Han, and S. Liu, "Effect of highly dispersed carbon nanotubes on the flexural toughness of cement-based composites," Construction and Building Materials, vol. 46, pp. 8-12, 2013.

[80] K. Habermehl-Cwirzen, V. Penttala, and A. Cwirzen, "Surface decoration of carbon nanotubes and mechanical properties of cement/carbon nanotube composites," Advances in Cement Research, vol. 20, no. 2, pp. 65-73, 2008.

[81] O. M. Dunens, K. J. Mackenzie, and A. T. Harris, "Synthesis of multiwalled carbon nanotubes on fly ash derived catalysts," Environmental Science \& Technology, vol. 43, no. 20, pp. 78897894, 2009.

[82] P. Ludvig, J. M. Calixto, L. O. Ladeira, and I. C. P. Gaspar, “Using converter dust to produce low cost cementitious composites by in situ carbon nanotube and nanofiber synthesis," Materials, vol. 4, no. 3, pp. 575-584, 2011.

[83] X. Zhang and Z. Liu, "Recent advances in microwave initiated synthesis of nanocarbon materials," Nanoscale, vol. 4, no. 3, pp. 707-714, 2012.

[84] P. Ludvig, J. M. Calixto, L. O. Ladeira, and I. C. P. Gaspar, "Using converter dust to produce low cost cementitious composites by in situ carbon nanotube and nanofiber synthesis," Materials, vol. 4, no. 3, pp. 575-584, 2010.

[85] S. Sun, X. Yu, B. Han, and J. Ou, "In situ growth of carbon nanotubes/carbon nanofibers on cement/mineral admixture particles: a review," Construction and Building Materials, vol. 49, pp. 835-840, 2013.

[86] H. M. Jennings, J. W. Bullard, J. J. Thomas, J. E. Andrade, J. J. Chen, and G. W. Scherer, "Characterization and modeling of pores and surfaces in cement paste: correlations to processing and properties," Journal of Advanced Concrete Technology, vol. 6, no. 1, pp. 5-29, 2008.

[87] F. Sanchez and A. Borwankar, "Multi-scale performance of carbon microfiber reinforced cement-based composites exposed to a decalcifying environment," Materials Science and Engineering A, vol. 527, no. 13-14, pp. 3151-3158, 2010.

[88] H. Manzano, J. S. Dolado, A. Guerrero, and A. Ayuela, "Mechanical properties of crystalline calcium-silicate-hydrates: comparison with cementitious C-S-H gels," Physica Status Solidi A: Applications and Materials Science, vol. 204, no. 6, pp. 17751780, 2007. 
[89] G. Constantinides and F.-J. Ulm, "The effect of two types of CS-H on the elasticity of cement-based materials: results from nanoindentation and micromechanical modeling," Cement and Concrete Research, vol. 34, no. 1, pp. 67-80, 2004.

[90] A. M. Brandt, J. Olek, I. H. Marshall, and A. M. Brandt, "Modification of mineral binding matrices carbon nanostructures," in Brittle Matrix Composites 9, p. 195, 2009.

[91] J. M. Makar, J. C. Margeson, and J. Luh, "Carbon nanotube/cement composites-early results and potential applications," in Proceedings of the 3rd International Conference on Construction Materials: Performance, Innovations and Structural Implications, pp. 1-10, Vancouver, Canada, August 2005.

[92] A. Chaipanich, T. Nochaiya, W. Wongkeo, and P. Torkittikul, "Compressive strength and microstructure of carbon nanotubes-fly ash cement composites," Materials Science and Engineering A, vol. 527, no. 4-5, pp. 1063-1067, 2010.

[93] X.-L. Xie, Y.-W. Mai, and X.-P. Zhou, "Dispersion and alignment of carbon nanotubes in polymer matrix: a review," Materials Science and Engineering R: Reports, vol. 49, no. 4, pp. 89-112, 2005.

[94] S. Xu, L. Gao, and W. Jin, "Production and mechanical properties of aligned multi-walled carbon nanotubes-M140 composites," Science in China, Series E: Technological Sciences, vol. 52, no. 7, pp. 2119-2127, 2009.

[95] R. K. Abu Al-Rub, A. I. Ashour, and B. M. Tyson, "On the aspect ratio effect of multi-walled carbon nanotube reinforcements on the mechanical properties of cementitious nanocomposites," Construction and Building Materials, vol. 35, pp. 647-655, 2012.

[96] J. Bae, J. Jang, and S.-H. Yoon, "Cure behavior of the liquidcrystalline epoxy/carbon nanotube system and the effect of surface treatment of carbon fillers on cure reaction," Macromolecular Chemistry and Physics, vol. 203, no. 15, pp. 2196-2204, 2002.

[97] A. Eitan, K. Jiang, D. Dukes, R. Andrews, and L. S. Schadler, "Surface modification of multiwalled carbon nanotubes: toward the tailoring of the interface in polymer composites," Chemistry of Materials, vol. 15, no. 16, pp. 3198-3201, 2003.

[98] G. Constantinides and F.-J. Ulm, "The nanogranular nature of C-S-H," Journal of the Mechanics and Physics of Solids, vol. 55, no. 1, pp. 64-90, 2007.

[99] Y. S. de Ibarra, J. J. Gaitero, E. Erkizia, and I. Campillo, "Atomic force microscopy and nanoindentation of cement pastes with nanotube dispersions," Physica Status Solidi A: Applications and Materials Science, vol. 203, no. 6, pp. 1076-1081, 2006.

[100] A. B. Abell, K. L. Willis, and D. A. Lange, "Mercury intrusion porosimetry and image analysis of cement-based materials," Journal of Colloid and Interface Science, vol. 211, no. 1, pp. 3944, 1999.

[101] S. P. Pandey and R. L. Sharma, "Influence of mineral additives on the strength and porosity of OPC mortar," Cement and Concrete Research, vol. 30, no. 1, pp. 19-23, 2000.

[102] T. Nochaiya and A. Chaipanich, "Behavior of multi-walled carbon nanotubes on the porosity and microstructure of cementbased materials," Applied Surface Science, vol. 257, no. 6, pp. 1941-1945, 2011.

[103] Y. Katsuda, P. Gerstel, J. Narayanan, J. Bill, and F. Aldinger, "Reinforcement of precursor-derived $\mathrm{Si}-\mathrm{C}-\mathrm{N}$ ceramics with carbon nanotubes," Journal of the European Ceramic Society, vol. 26, no. 15, pp. 3399-3405, 2006.

[104] F. Inam, H. Yan, T. Peijs, and M. J. Reece, “The sintering and grain growth behaviour of ceramic-carbon nanotube nanocomposites," Composites Science and Technology, vol. 70, no. 6, pp. 947-952, 2010.

[105] S. Bi, G. Hou, X. Su, Y. Zhang, and F. Guo, "Mechanical properties and oxidation resistance of $\alpha$-alumina/multi-walled carbon nanotube composite ceramics," Materials Science and Engineering A, vol. 528, no. 3, pp. 1596-1601, 2011.

[106] N. Lachman, E. Wiesel, R. Guzman de Villoria, B. L. Wardle, and H. D. Wagner, "Interfacial load transfer in carbon nanotube/ceramic microfiber hybrid polymer composites," Composites Science and Technology, vol. 72, no. 12, pp. 1416-1422, 2012.

[107] M. Estili and A. Kawasaki, "An approach to mass-producing individually alumina-decorated multi-walled carbon nanotubes with optimized and controlled compositions," Scripta Materialia, vol. 58, no. 10, pp. 906-909, 2008.

[108] R. Z. Ma, J. Wu, B. Q. Wei, J. Liang, and D. H. Wu, "Processing and properties of carbon nanotubes-nano-SiC ceramic," Journal of Materials Science, vol. 33, no. 21, pp. 5243-5246, 1998.

[109] G. Hwang and K. Hwang, "Carbon nanotube reinforced ceramics," Journal of Materials Chemistry, vol. 11, no. 6, pp. 1722-1725, 2001.

[110] Z. H. Xia, J. Lou, and W. A. Curtin, "A multiscale experiment on the tribological behavior of aligned carbon nanotube/ceramic composites," Scripta Materialia, vol. 58, no. 3, pp. 223-226, 2008.

[111] Z. Xia, L. Riester, W. A. Curtin et al., "Direct observation of toughening mechanisms in carbon nanotube ceramic matrix composites," Acta Materialia, vol. 52, no. 4, pp. 931-944, 2004.

[112] J. M. Makar and G. W. Chan, "Growth of cement hydration products on single-walled carbon nanotubes," Journal of the American Ceramic Society, vol. 92, no. 6, pp. 1303-1310, 2009.

[113] H. Kwon, M. Estili, K. Takagi, T. Miyazaki, and A. Kawasaki, "Combination of hot extrusion and spark plasma sintering for producing carbon nanotube reinforced aluminum matrix composites," Carbon, vol. 47, no. 3, pp. 570-577, 2009.

[114] M. Estili, A. Kawasaki, H. Sakamoto, Y. Mekuchi, M. Kuno, and T. Tsukada, "The homogeneous dispersion of surfactantless, slightly disordered, crystalline, multiwalled carbon nanotubes in $\alpha$-alumina ceramics for structural reinforcement," Acta Materialia, vol. 56, no. 15, pp. 4070-4079, 2008.

[115] G. Yamamoto, K. Shirasu, T. Hashida et al., "Nanotube fracture during the failure of carbon nanotube/alumina composites," Carbon, vol. 49, no. 12, pp. 3709-3716, 2011.

[116] E. M. Byrne, A. Letertre, M. A. McCarthy, W. A. Curtin, and Z. Xia, "Optimizing load transfer in multiwall nanotubes through interwall coupling: theory and simulation," Acta Materialia, vol. 58, no. 19, pp. 6324-6333, 2010.

[117] F. Pavia and W. A. Curtin, "Interfacial sliding in carbon nanotube/diamond matrix composites," Acta Materialia, vol. 59, no. 17, pp. 6700-6709, 2011.

[118] F. Pavia and W. A. Curtin, "Optimizing strength and toughness of nanofiber-reinforced CMCs," Journal of the Mechanics and Physics of Solids, vol. 60, no. 9, pp. 1688-1702, 2012.

[119] E. M. Byrne, M. A. McCarthy, and W. A. Curtin, "Pullout of rough multiwall carbon nanotubes: a parametric study," Composites Part A: Applied Science and Manufacturing, vol. 56, pp. 93-102, 2014.

[120] M. Estili and A. Kawasaki, "Engineering strong intergraphene shear resistance in multi-walled carbon nanotubes and dramatic tensile improvements," Advanced Materials, vol. 22, no. 5, pp. 607-610, 2010. 
[121] J. Wang, H. Kou, X. Liu, Y. Pan, and J. Guo, "Reinforcement of mullite matrix with multi-walled carbon nanotubes," Ceramics International, vol. 33, no. 5, pp. 719-722, 2007.

[122] B. Han, Z. Yang, X. Shi, and X. Yu, "Transport properties of carbon-nanotube/cement composites," Journal of Materials Engineering and Performance, vol. 22, no. 1, pp. 184-189, 2013.

[123] S. Wansom, N. J. Kidner, L. Y. Woo, and T. O. Mason, "ACimpedance response of multi-walled carbon nanotube/cement composites," Cement and Concrete Composites, vol. 28, no. 6, pp. 509-519, 2006.

[124] L. Coppola, A. Buoso, and F. Corazza, "Electrical properties of carbon nanotubes cement composites for monitoring stress conditions in concrete structures," Applied Mechanics and Materials, vol. 82, pp. 118-123, 2011.

[125] G. Y. Li, P. M. Wang, and X. Zhao, "Pressure-sensitive properties and microstructure of carbon nanotube reinforced cement composites," Cement and Concrete Composites, vol. 29, no. 5, pp. 377-382, 2007.

[126] X. Yu and E. Kwon, "A carbon nanotube/cement composite with piezoresistive properties," Smart Materials and Structures, vol. 18, no. 5, Article ID 055010, 2009.

[127] B. Han, X. Yu, and J. Ou, "Effect of water content on the piezoresistivity of MWNT/cement composites," Journal of Materials Science, vol. 45, no. 14, pp. 3714-3719, 2010.

[128] B. Han, X. Yu, E. Kwon, and J. Ou, "Effects of CNT concentration level and water/cement ratio on the piezoresistivity of CNT/cement composites," Journal of Composite Materials, vol. 46, no. 1, pp. 19-25, 2012.

[129] W. Song, C. Jeon, Y. S. Kim et al., "Synthesis of bandgapcontrolled semiconducting single-walled carbon nanotubes," ACS Nano, vol. 4, no. 2, pp. 1012-1018, 2010.

[130] W.-H. Chiang and R. M. Sankaran, "Linking catalyst composition to chirality distributions of as-grown single-walled carbon nanotubes by tuning $\mathrm{Ni}_{x} \mathrm{Fe}_{1-x}$ nanoparticles," Nature Materials, vol. 8, no. 11, pp. 882-886, 2009.

[131] H. Qiu, G. Yang, B. Zhao, and J. Yang, "Catalyst-free synthesis of multi-walled carbon nanotubes from carbon spheres and its implications for the formation mechanism," Carbon, vol. 53, pp. 137-144, 2013.

[132] Y. Su, P. Zhou, J. Zhao, Z. Yang, and Y. Zhang, "Large-scale synthesis of few-walled carbon nanotubes by DC arc discharge in low-pressure flowing air," Materials Research Bulletin, vol. 48, no. 9, pp. 3232-3235, 2013.

[133] M. Uo, T. Akasaka, F. Watari, Y. Sato, and K. Tohji, "Toxicity evaluations of various carbon nanomaterials," Dental Materials Journal, vol. 30, no. 3, pp. 245-263, 2011.

[134] K. A. D. Guzmán, M. R. Taylor, and J. F. Banfield, "Environmental risks of nanotechnology: national nanotechnology initiative funding, 2000-2004," Environmental Science and Technology, vol. 40, no. 5, pp. 1401-1407, 2006.

[135] A. J. Kennedy, M. S. Hull, J. A. Steevens et al., "Factors influencing the partitioning and toxicity of nanotubes in the aquatic environment," Environmental Toxicology and Chemistry, vol. 27, no. 9, pp. 1932-1941, 2008.

[136] A. Schierz and H. Zänker, "Aqueous suspensions of carbon nanotubes: surface oxidation, colloidal stability and uranium sorption," Environmental Pollution, vol. 157, no. 4, pp. 10881094, 2009.

[137] V. L. Colvin, "The potential environmental impact of engineered nanomaterials," Nature Biotechnology, vol. 21, no. 10, pp. 1166-1170, 2003.
[138] O. Vittorio, V. Raffa, and A. Cuschieri, "Influence of purity and surface oxidation on cytotoxicity of multiwalled carbon nanotubes with human neuroblastoma cells," Nanomedicine: Nanotechnology, Biology, and Medicine, vol. 5, no. 4, pp. 424431, 2009.

[139] X. Wang, G. Jia, H. Wang et al., "Diameter effects on cytotoxicity of multi-walled carbon nanotubes," Journal of Nanoscience and Nanotechnology, vol. 9, no. 5, pp. 3025-3033, 2009.

[140] M. Bottini, S. Bruckner, K. Nika et al., "Multi-walled carbon nanotubes induce T lymphocyte apoptosis," Toxicology Letters, vol. 160, no. 2, pp. 121-126, 2006.

[141] A. Takagi, A. Hirose, T. Nishimura et al., "Induction of mesothelioma in $553+/-$ mouse by intraperitoneal application of multiwall carbon nanotube," The Journal of Toxicological Sciences, vol. 33, no. 1, pp. 105-116, 2008.

[142] J. Muller, F. Huaux, N. Moreau et al., "Respiratory toxicity of multi-wall carbon nanotubes," Toxicology and Applied Pharmacology, vol. 207, no. 3, pp. 221-231, 2005.

[143] C. A. Poland, R. Duffin, I. Kinloch et al., "Carbon nanotubes introduced into the abdominal cavity of mice show asbestoslike pathogenicity in a pilot study," Nature Nanotechnology, vol. 3, no. 7, pp. 423-428, 2008.

[144] C.-W. Lam, J. T. James, R. McCluskey, S. Arepalli, and R. L. Hunter, "A review of carbon nanotube toxicity and assessment of potential occupational and environmental health risks," Critical Reviews in Toxicology, vol. 36, no. 3, pp. 189-217, 2006.

[145] V. C. Li and K. H. Obla, "Effect of fiber length variation on tensile properties of carbon-fiber cement composites," Composites Engineering, vol. 4, no. 9, pp. 947-964, 1994.

[146] N. Banthia, S. Djeridane, and M. Pigeon, "Electrical resistivity of carbon and steel micro-fiber reinforced cements," Cement and Concrete Research, vol. 22, no. 5, pp. 804-814, 1992.

[147] Y. Wang, V. C. Li, and S. Backer, "Tensile properties of synthetic fiber reinforced mortar," Cement and Concrete Composites, vol. 12, no. 1, pp. 29-40, 1990.

[148] F. Pelisser, A. B. D. S. S. Neto, H. L. L. Rovere, and R. C. D. A. Pinto, "Effect of the addition of synthetic fibers to concrete thin slabs on plastic shrinkage cracking," Construction and Building Materials, vol. 24, no. 11, pp. 2171-2176, 2010.

[149] B. Benmokrane, O. Chaallal, and R. Masmoudi, "Glass fibre reinforced plastic (GFRP) rebars for concrete structures," Construction and Building Materials, vol. 9, no. 6, pp. 353-364, 1995.

[150] P. Trens, R. Denoyel, and E. Guilloteau, "Evolution of surface composition, porosity, and surface area of glass fibers in a moist atmosphere," Langmuir, vol. 12, no. 5, pp. 1245-1250, 1996.

[151] W. Yao, J. Li, and K. Wu, "Mechanical properties of hybrid fiberreinforced concrete at low fiber volume fraction," Cement and Concrete Research, vol. 33, no. 1, pp. 27-30, 2003.

[152] Ş. Yazici, G. Inan, and V. Tabak, "Effect of aspect ratio and volume fraction of steel fiber on the mechanical properties of SFRC," Construction and Building Materials, vol. 21, no. 6, pp. 1250-1253, 2007.

[153] Z. S. Metaxa, J.-W. T. Seo, M. S. Konsta-Gdoutos, M. C. Hersam, and S. P. Shah, "Highly concentrated carbon nanotube admixture for nano-fiber reinforced cementitious materials," Cement and Concrete Composites, vol. 34, no. 5, pp. 612-617, 2012.

[154] A. Cwirzen, K. Habermehl-Cwirzen, A. G. Nasibulin, E. I. Kaupinen, P. R. Mudimela, and V. Penttala, "SEM/AFM studies of cementitious binder modified by MWCNT and nano-sized Fe needles," Materials Characterization, vol. 60, no. 7, pp. 735740, 2009. 
[155] J. Bharj, S. Singh, S. Chander, and R. Singh, "Experimental study on compressive strength of cement-CNT composite paste," Indian Journal of Pure \& Applied Physics, vol. 52, no. 1, pp. 35-38, 2014.

[156] J. Zuo, W. Yao, and K. Wu, "Seebeck effect and mechanical properties of carbon nanotube-carbon fiber/cement nanocomposites," Fullerenes Nanotubes and Carbon Nanostructures, vol. 23, no. 5, pp. 383-391, 2015.

[157] H. K. Kim, I. W. Nam, and H. K. Lee, "Enhanced effect of carbon nanotube on mechanical and electrical properties of cement composites by incorporation of silica fume," Composite Structures, vol. 107, pp. 60-69, 2014.

[158] Q. Liu, W. Sun, H. Jiang, and C. Wang, "Effects of carbon nanotubes on mechanical and 2D-3D microstructure properties of cement mortar," Journal Wuhan University of TechnologyMaterials Science Edition, vol. 29, no. 3, pp. 513-517, 2014.

[159] R. Hamzaoui, S. Guessasma, B. Mecheri, A. M. Eshtiaghi, and A. Bennabi, "Microstructure and mechanical performance of modified mortar using hemp fibres and carbon nanotubes," Materials \& Design, vol. 56, pp. 60-68, 2014.

[160] B. Wang, Y. Han, and T. Zhang, "Reinforcement of surfacemodified multi-walled carbon nanotubes on cement-based composites," Advances in Cement Research, vol. 26, no. 2, pp. 7784, 2014.

[161] M. S. Morsy, S. H. Alsayed, and M. Aqel, "Hybrid effect of carbon nanotube and nano-clay on physico-mechanical properties of cement mortar," Construction and Building Materials, vol. 25, no. 1, pp. 145-149, 2011.

[162] G. Yakovlev, J. Kerienè, A. Gailius, and I. Girniene, "Cementbased foam concrete reinforced by carbon nanotubes," Materials Science, vol. 12, pp. 147-151, 2006.

[163] K. Wille and K. J. Loh, "Nanoengineering ultra-highperformance concrete with multiwalled carbon nanotubes," Transportation Research Record, no. 2142, pp. 119-126, 2010.

[164] X. Wang, I. Rhee, Y. Wang, and Y. Xi, "Compressive strength, chloride permeability, and freeze-thaw resistance of MWNT concretes under different chemical treatments," The Scientific World Journal, vol. 2014, Article ID 572102, 8 pages, 2014.

[165] J. Keriene, M. Kligys, A. Laukaitis, G. Yakovlev, A. Špokauskas, and M. Aleknevičius, "The influence of multi-walled carbon nanotubes additive on properties of non-autoclaved and autoclaved aerated concretes," Construction and Building Materials, vol. 49, pp. 527-535, 2013. 

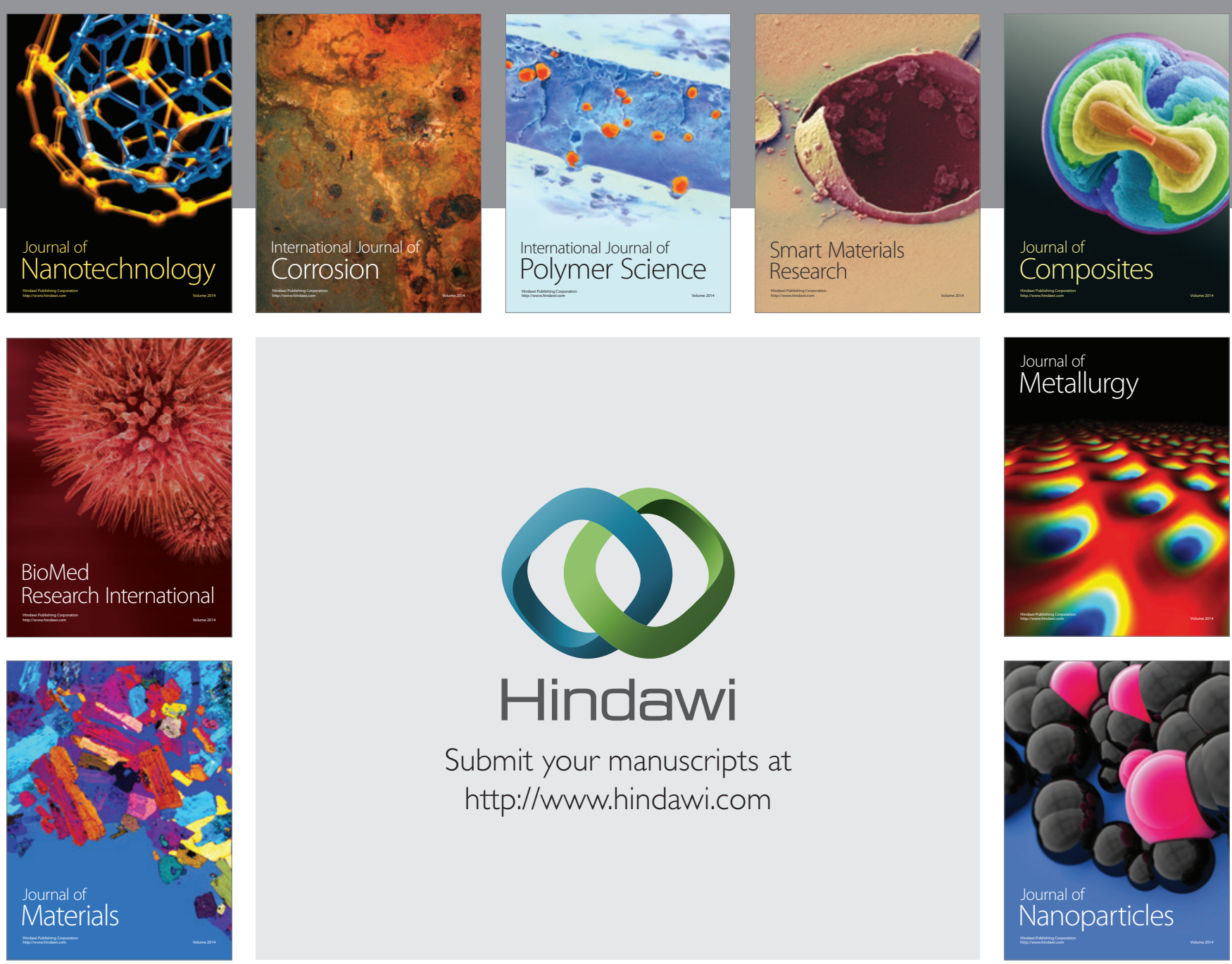

Submit your manuscripts at http://www.hindawi.com
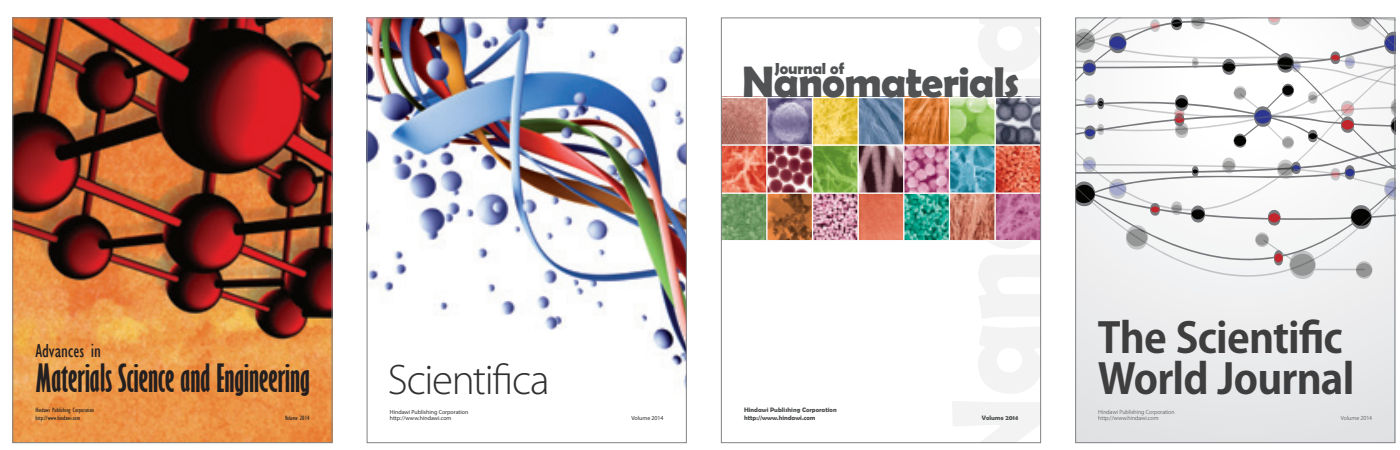

\section{The Scientific World Journal}
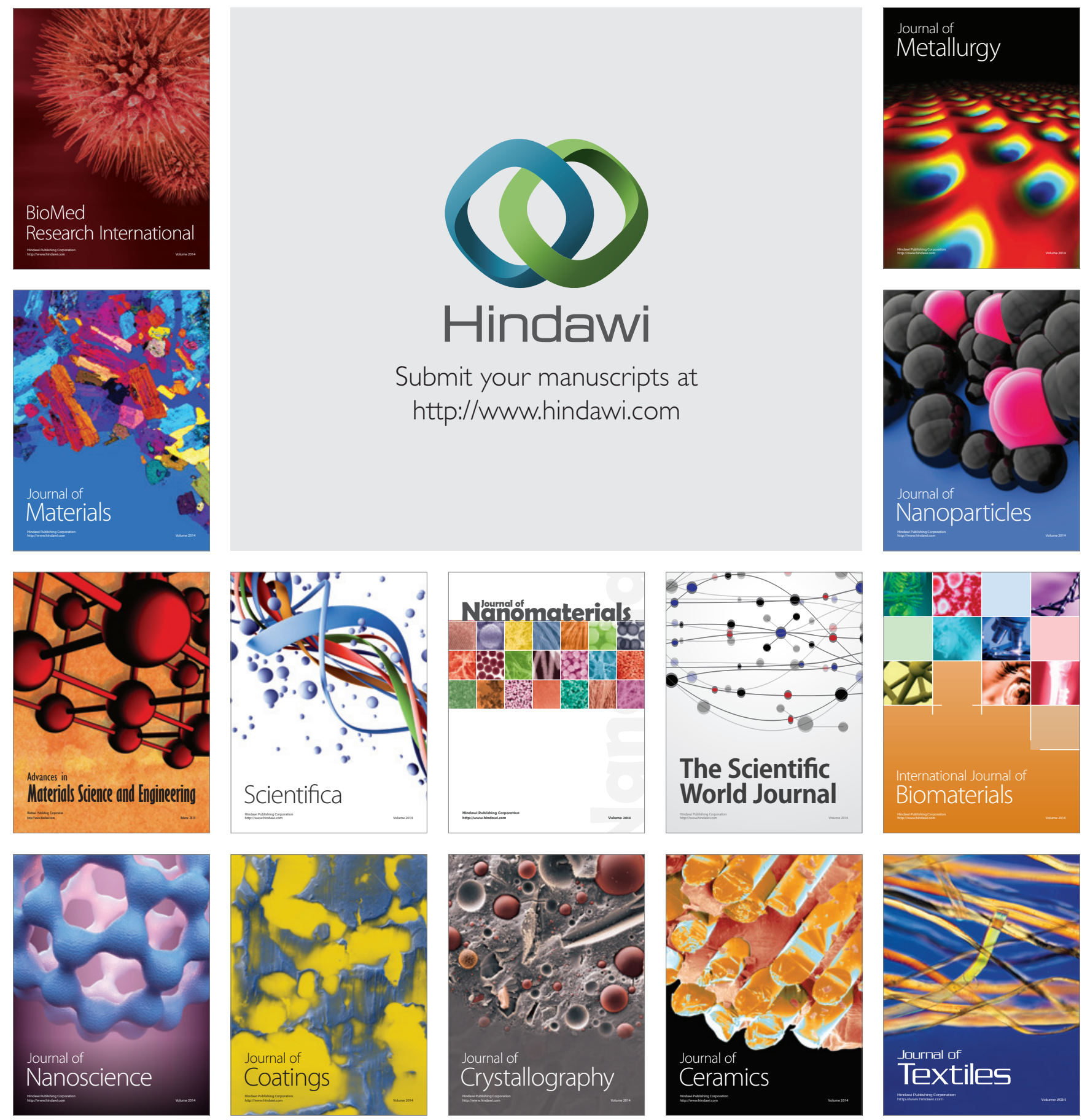